
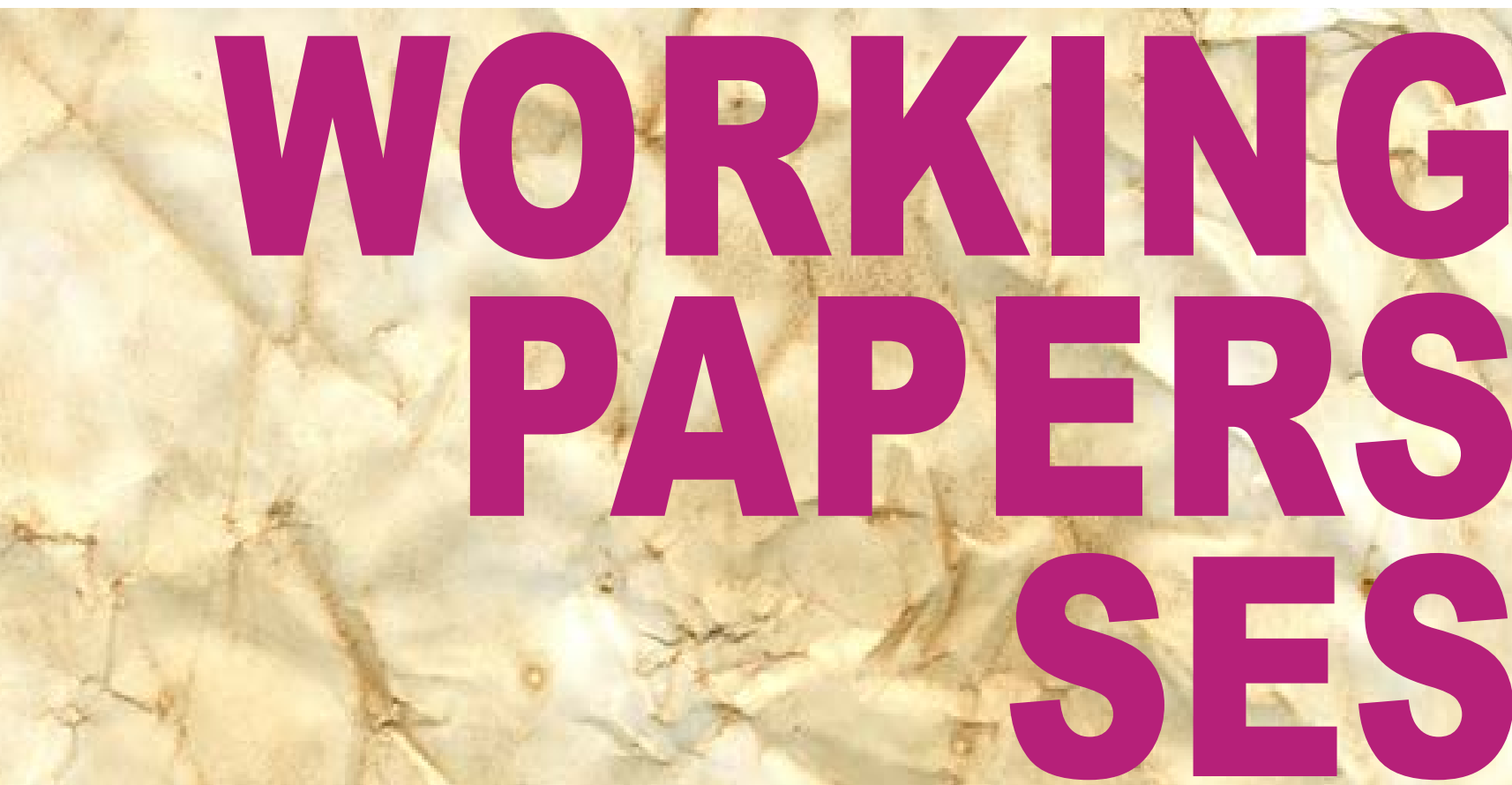

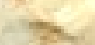

A Productive Clash of

Cultures:

Injecting Economics into

Leadership Research

Christian Zehnder, Holger Herz and

Jean-Philippe Bonardi 


\title{
A Productive Clash of Cultures: Injecting Economics into Leadership Research
}

\author{
Christian Zehnder, Holger Herz and Jean-Philippe Bonardi ${ }^{1}$
}

\author{
Forthcoming in: The Leadership Quarterly \\ http://dx.doi.org/10.1016/j.leaqua.2016.10.004
}

September 2016

\begin{abstract}
Research on leadership in economics has developed in parallel to the literature in management and psychology and links between the fields have been sparse. Whereas modern leadership scholars mostly focus on transformational and related leadership styles, economists have mainly emphasized the role of contracts, control rights, and incentives. We argue that both fields could profit from enriching their approach with insights from the other field. We review and synthesize the economics literature on leadership in organizations and discuss how leadership scholars in management and psychology can benefit from the detailed understanding of transactional methods that economists have developed. We link the contributions in economics to a broad set of topics including the foundations of leadership, leader emergence, and leader effectiveness. At the same time, we also point out limitations of the economic approach and outline how the integration of leadership research and economics would broaden the scope of future studies.
\end{abstract}

Keywords: Leadership, Economics, Foundations, Emergence, Effectiveness.

1 Zehnder: University of Lausanne, email: christian.zehnder@unil.ch; Herz: University of Fribourg, email:holger.herz@unifr.ch, Bonardi: University of Lausanne, email: jean-philippe.bonardi@unil.ch. We thank Shelly Dionne for her constructive comments and Lino Eden for excellent research assistance. 


\section{Introduction}

Although leadership is not yet an established subfield of economics, elements of leadership feature prominently in some areas of economic research. At the same time, a vast literature on leadership exists in psychology and management. These two literatures have so far moved mostly in parallel to each other and links between the fields have been sparse, despite obvious commonalities. In light of the fact that much of the relevant work in economics most directly applies to leadership in organizations, we will restrict our attention to this type of leadership. Of course, we acknowledge that leadership applies more broadly and is also relevant in many other dimensions of human society, but it is mostly in the context of organizations, where we think that both economists and leadership scholars could benefit tremendously from a more intense exchange of ideas and insights. Whereas inter-disciplinary approaches are interesting in general, the complementarity of the two existing literatures makes this case particularly promising and fruitful. We identify three themes within which synergies between the fields seem obvious: (1) Why is leadership needed at all?, (2) Who emerges as a leader?, and (3) How can a leader be effective?

In the first part of our article we explore the foundations of leadership in the context of economic activity. In light of the omnipresence of leader-follower relationships in real-life organizations asking whether and why leadership is important in the economic context may seem superfluous. But this argument is misleading. From an economic point of view the question of why leadership is needed at all is a highly interesting one. Economic theory implies that in the absence of frictions it is most efficient if economic transactions are governed by the price mechanism in a competitive market. In reality, however, we observe that a significant part of economic activity takes place in vertically structured, hierarchical organizations rather than in markets. So, how can this discrepancy be explained? The literature on the theory of the firm provides answers (Coase, 1937, Williamson, 1975, 1985, Alchian and Demsetz, 1972). Organizational economists have identified a number of reasons for why market mechanisms fail to operate properly in some situations. Among the main obstacles that reduce market efficiency are excessive transactions costs (Coase 1937), exploitation (Williamson, 1975, 1985), lack of teamwork (Alchian and Demsetz, 1972), and distorted incentives (Holmström 1999a). We will show that in all those situations the establishment of vertical, authority-based leader-follower relations within organizations can help to mitigate the problem. Thus, in general, the need for leadership in organizations is driven by the failure of the market. Moreover, each approach discussed in this section will reveal new elements that need to be added to the leader's task portfolio, creating a rich profile of leader responsibilities. 
In the second part of the paper we shift our attention to the problem of leader emergence. The leadership literature dedicated to this topic is mostly concerned with individual traits of people who emerge as leaders (Lord, De Vader and Alliger, 1986; Judge, Bono, Ilies and Gerhardt, 2002). In economics, in contrast, research related to leader emergence focusses on how features of organizational design (most importantly ownership structures and delegation decisions) shape incentives of particular individuals to become a leader (Aghion and Tirole, 1997). We will argue that there are important and interesting links between these two views. The strength of the economic approach is that it determines the conditions under which a motivated leader can and will emerge. If ownership is well defined, economic models analyze how knowledge dispersion and alignment of interest affect the owners' capability to effectively appoint desirable leaders. If ownership structures are vague, the theory identifies incentive structures to induce motivated leaders to step up voluntarily. However, the economic approach is somewhat agnostic regarding the origins of people's motivation to lead. In reality, it matters greatly for an organization whether the appointed or emerged leader is suitable for the task at hand. To design systems that ensure that the right person gets selected, it is therefore important to understand how appealing different incentive systems are to people with particular personality traits. We argue that the development of such general models of leader emergence requires that economists and leadership scholars share and combine their insights.

In the third and final part of the article we turn to leader effectiveness. We believe that the respective literatures on effectiveness exhibit even stronger complementarities than the ones on foundations and emergence. Effectiveness research in management and psychology has mostly focused on what has been termed the "new" leadership by Bryman (1992). This approach includes work on transformational and charismatic leadership, has a strong focus on valuebased methods, and assumes that leaders motivate followers intrinsically (Burns, 1978 and Bass, 1985; House, 1977; Shamir, House and Arthur, 1993). Proponents of this literature typically argue that effective leadership needs to go beyond purely transactional measures such as rewards and sanctions (House, 1977, Howell and Avolio 1993). The literature in economics, in contrast, has essentially taken an opposite approach. Economists have extensively studied the optimal design of contracts and incentives and have developed a detailed understanding of the environmental conditions under which contract-based (i.e., transactional) leadership techniques work or fail (Jensen and Meckling, 1976, Hart and Holmström, 1987, Milgrom and Homström, 1991). ${ }^{2}$ The fact that leaders may also be able to use

\footnotetext{
${ }^{2}$ Note that the way we use the concepts of transactional and transformational leadership throughout the paper may not always perfectly coincide with the detailed definitions and operationalizations used in the leadership literature. The reason is that we aim
} 
different, potentially softer channels to affect followers' behavior has been largely ignored by economists, however. We think that both approaches are too narrow. We argue that truly effective leadership means that the leader always chooses the leadership style best suited to the situation in which the leader needs to lead (see also, House, 1996). In some cases, a purely transactional approach may be best, in other cases, transformational tactics may be required. ${ }^{3}$ Our review of the literature shows that the economic framework provides a very systematic and simple tool to distinguish situations in which a contractual solution based on rewards and sanctions is sufficient from those in which a more involved, transformational approach is needed. This allows us to present a simple characterization that hints at the optimal leadership style as a function of the environment and identifies environmental complexity as the central determinant. A simple rule of thumb is that transactional, incentive-based systems work better in simple environments. Investment-intense transformational approaches are likely to be most effective in complex situations in which incentives would either be ineffective or would even lead to unwanted distortions (Shamir et al., 1993). Building on recent developments in the literature on identity economics (Akerlof and Kranton, 2000, 2005) we propose a way to fully integrate the two approaches in a unified framework that will be able to provide insights beyond the limitations of each of the current approaches.

Our article is not the first one to provide a review of the economics literature on leadership. However, we believe that our approach to the topic differs in quite fundamental ways from what others have done before us. Most importantly, both Hermalin (2013) and Bolton, Brunnermeier and Veldkamp (2013a) take the view that the literature on explicit performance pay is not part of leadership and concentrate on leader activities that go beyond contract design. Hermalin (2013) mainly focuses on the leader's role as a conveyor of information in situations with information asymmetries and highlights leading by sacrifice and leading by example as important solutions that allow the leader to send credible signals to followers even if the leader's and the follower's interests are not perfectly aligned. Bolton, Brunnermeier and Veldkamp (2013a) review research on delegation, communication and coordination, and additionally provide an

at connecting two literatures with different traditions, frameworks, and models, so that some flexibility is needed. We are convinced, however, that we use the terms correctly at the conceptual level. Judge and Piccolo (2004), for example, state that transactional leaders "focus on the proper exchange of resources", whereas transformational leaders "offer a purpose that transcends short-term goals and focuses on higher order intrinsic needs". When translated to the language of economists the former corresponds to the design of contracts, incentive systems and proper organizational institutions and the latter is related to attempts to shape followers' preferences. We think it is most promising to start linking the literatures at this higher level, where it is easier to find connecting points. Contradictions in the details need to be sorted out once the common ground is understood.

${ }^{3}$ We are aware of the fact that the transactional-transformational dichotomy does not cover all aspects of leadership and that there exist other avenues such as expert-based approaches that rely neither on values nor on contracts (Antonakis and House, 2014). However, to keep things manageable in the context of this paper, we put our focus on the transactional-transformational part, but point out links to other approaches (such as instrumental leadership) when the context requires it. 
economic model for some specific elements of leadership, such as vision, communication, execution and integrity (see also Bolton, Brunnermeier and Veldkamp, 2013b). In this article, in contrast, we embrace a broader and more inclusive definition of leadership which considers both transactional and transformational aspects of leadership, where the transactional part explicitly includes contractual solutions. We find this perspective useful because it allows us to illustrate the full set of methods available to a leader and to emphasize that it is of crucial importance that the leadership strategy is picked in response to the characteristics of the particular environment in which the leader operates.

Our paper reviews and builds on various approaches in economics ranging from game theory, information economics, institutional and organizational economics, to behavioral and experimental research. Economics offers a number of powerful methodological tools including formal modeling, econometrics, and incentivized experiments. At least for some of the research questions of interest to leadership scholars these tools can be highly useful, as is evident from the fact that some leadership scholars have already started using them (see e.g. Kulas et al., 2013, Oc et al., 2015, Grabo and van Vugt, in press, or Bendahan et al., 2015). ${ }^{4}$ We hope that our review points out the strengths of these approaches and further motivates leadership researchers to make use of them in their future work.

Our focus on the organizational context naturally implies that there are important branches of leadership research in economics that we do not cover in this review. In fact, economists have studied aspects of leadership from many different perspectives and in many different contexts. Among other things economists have investigated the impact of political leaders on economic outcomes (Jones and Olken, 2005), policy (Chattopadhyay and Duflo, 2004) and education (Clots-Figuerasa, 2012), the role of gender in political and corporate leadership (Gangadharan et al, in press, Matsa and Miller, 2013) and the impact of ethical and unethical leaders on followers behavior in the moral dimension (d'Adda et al., in press). In the interest of keeping our work within reasonable bounds, we see us forced to leave it to others to cover these (and other) interesting developments in the economics literature and to establish the corresponding links to the leadership field.

The remainder of the paper is structured as follows. The next section recapitulates the basic concepts used in economic analysis and discusses the economic foundations of leadership. The subsequent two sections review existing work in economics on leader emergence and leader effectiveness, discuss how this work is linked to the corresponding

\footnotetext{
${ }^{4}$ See also Sturm and Antonakis (2015), for a discussion of the need to use game theoretic models in research on interpersonal power.
} 
literature in psychology and management, and point out interesting future avenues for research that combines insights from both fields. The final section concludes.

\section{Economic Foundations of Leadership}

\section{Basics of Economic Theory}

Because this paper views leadership through the lens of economic theory, it is useful to first review the basic concepts on which the economic framework builds. Economics is based on the assumption that people's behavior is driven by their rational desire to maximize their well-being (or utility). Which action a decision maker picks out of a given set of alternatives is determined by three components: i) preferences, ii) beliefs, and iii) outcomes (see e.g., Mas-Colell et al. 1995). Preferences represent a person's tastes, that is, they define what a decision maker likes or dislikes. Preferences are typically represented by utility functions, which order outcomes in terms of implied well-being. ${ }^{5}$ Beliefs represent a decision maker's expectations about behavior of other people and/or about the relevant state of the world. Outcomes are the consequences implied by a particular decision or a combination of decisions. ${ }^{6}$ The economic framework therefore suggests that leaders can potentially shape follower behavior by influencing their preferences, their beliefs, their outcomes, or their choice sets. Traditionally, economists have assumed that preferences are exogenous — that is, fixed and impossible to change. Much of the existing literature that we discuss is therefore concerned with leader activities that either affect followers' beliefs, outcomes or choice sets. However, the traditional view is currently being challenged and economists have started working on models in which preferences are endogenous and can change in response to both own decisions and decisions of others. This newly emerging line of work has important implications, because it provides a way to naturally integrate important insights from the literature on transformational leadership into the economic framework (e.g. the creation of visions, missions and identities). We will carefully explore these implications when we discuss promising avenues for future research on the economics of leadership.

Another important aspect of the economic approach is that decisions are always regarded as trade-offs. Each available option, including organizational choices, has advantages and disadvantages and therefore the determination of the

\footnotetext{
${ }^{5}$ Neoclassical economics typically assumes that people's utility is solely driven by their own material payoffs. However, over the last three decades behavioral economists have challenged these narrow assumptions and have developed alternative utility models which also take into account social motives such as fairness, status seeking, envy etc.

${ }^{6}$ It is important to emphasize that outcomes do not only consist of monetary or material payoffs alone, but may also incorporate non-physical or psychological elements such as, for example, cognitive effort costs or received recognition.
} 
optimal decision requires a cost-benefit-analysis in which one option is always compared to another. Typically, the cost and benefits of each alternative depend on the situation at hand. ${ }^{7}$ This implies that in many cases there is no globally best alternative. This will also be the case in this article. In the next section, for example, we will argue that it is important to reflect about the question of whether and when leadership is needed at all. We will see that there are cases in which no vertical relationship between a leader and follower is needed to organize a transaction, because it is most efficient to use a market mechanism in which no hierarchy exists. In other cases, in contrast, having a leader is crucial to guarantee efficient operations. Likewise, in the section on leader effectiveness we will see that there is no overall dominant leadership style. Whether it is best to rely on a particular style is determined by the environment.

Why does leadership matter at all? - Market Failure as a Justification for the Need for Leadership

A first and fundamentally important question that every researcher interested in leadership should think about is: "Why do human societies need leaders at all?" In light of the fact that leaders are omnipresent in almost all dimensions of our social and economic life, this question may seem trivial at first sight. However, from a theoretical point of view, finding an answer is, in fact, quite interesting and challenging. In the context of this paper, we are predominantly interested in understanding leadership in the context of organizations. So, for our purpose, the central question is: "Why are leaders needed for carrying out economic transactions?" ${ }^{8}$ One of the central results in standard microeconomic theory states that a pure market economy tends to lead to a Pareto efficient allocation of resources (this is called the first theorem of welfare economics, see Arrow, 1951, Debreu, 1951 and Arrow and Debreu, 1954). According to this theorem, economic activity should predominantly take place in horizontal market structures and there should be little, if any demand for leadership.

Simon (1991) presents an intriguing thought experiment illustrating that a typical real-life economy is far away from such a pure market system: "A mythical visitor from Mars [...] approaches the Earth from space, equipped with a telescope that reveals social structures. The firms reveal themselves, say, as solid green areas [...]. Market transactions show as red lines connecting firms [...]. A message sent back home, describing the scene, would speak of 'large green areas interconnected by red lines'. It would not likely speak of 'a network of red lines connecting green spots'. [...].Our visitor might be surprised to hear the structure called a market economy. 'Wouldn't

\footnotetext{
${ }^{7}$ Note that costs and benefits do not have to be monetary but can also be psychological in nature (e.g., psychological costs of norm violation or psychological benefits of helping a needy person).

${ }^{8}$ Obviously, the fact that we focus on the organizational context does not mean that this question is not relevant in other contexts as well. On the contrary, we hope that future research also explores the foundations of leadership more broadly.
} 
organizational economy' be the more appropriate term?" it might ask". It is a fact that much of our economic activity takes place in organizations characterized by hierarchical leader-follower relationships and not in decentralized markets with horizontal structures (Hart, 2008). But why has such a structure arisen?

In this section we argue that one important reason for the need for leadership in the context of economic transactions is that market mechanisms do not always work efficiently. In some situations, market exchanges lead to excessive search or bargaining costs. In other cases, markets generate the potential for exploitation and therewith undermine investment incentives, limit cooperation, or trigger free-riding. Or markets can create misaligned incentives which foster counter-productive behavior such as cheating or sabotage. We will show that many of these problems can be resolved or at least mitigated when transactions are embedded in vertical, leader-follower structures.

Ronald Coase was one of the first economists who systematically thought about the endogenous emergence of hierarchical organizations in a market economy. In his seminal paper Coase (1937) abolished the prevailing zero transaction cost assumption and argued that search and bargaining imply that obtaining a good or service on the market has a cost that amounts to more than just the price. Coase argued that carrying out a transaction inside an organization (or firm) reduces these additional costs, because the hierarchical structure inside the firm provides the leader (or entrepreneur) with the authority to dictate the terms of trade to his employees (within reasonable limits). According to Coase replacing horizontal market activities with authority-based leader-follower interactions is efficient if transaction costs are substantial.

Transaction cost economics, pioneered by Oliver Williamson (Williamson, 1975, 1985), extended Coase's reasoning and argued that market exchange functions well as long as transactions involve only simple and/or generic products or services. Problems arise when economic exchanges become complex so that specific investments are required and trading partners become dependent on each other. Dependencies create incentives for opportunistic behavior and increase the potential for conflict about the division of surplus (this is often termed the hold-up problem). According to Williamson, integrating complex transactions into organizations is beneficial because authority in hierarchical structures allows limiting the scope for opportunism and hold-up. However, integrating a transaction into a firm also gives rise to new challenges. The lack of the invisible hand of the market implies that firms tend to suffer from coordination and motivation problems. Transaction cost economics therefore calls for a richer role of leadership than the earlier work of Coase: effective leaders should not only use their formal authority to diminish inefficiencies caused by search, haggling and opportunistic behavior, but they also need to foster coordination and cooperation within their 
workforce. Moreover, because there is an imminent danger that the leader herself ${ }^{9}$ abuses her power for opportunistic reasons, careful leader selection and institutional safeguards are of crucial importance.

Alchian and Demsetz (1972) developed an alternative or complementary theory. In their view leaders are needed, because markets fail to implement efficient team production. If collaboration is essential, but individual contributions are hard to observe, a natural free-riding problem arises. The information problem implies that market competition is not a perfect solution. Alchian and Demsetz therefore propose the appointment of a leader who is the residual claimant of the net returns produced by the team. The leader is important for two reasons. First, the leader needs to engage in costly monitoring of individual contributions. Monitoring is efficient as long as the value added by effective teamwork outweighs the cost. Second, the leader needs to ensure that contributors are rewarded and free-riders are excluded. Thus, this approach adds two new elements to the task portfolio of the leader: monitoring (measuring followers' inputs) and selection (exclusion of free-riding followers).

Building on ideas from both the previously discussed approaches Holmström (1999a) develops the idea that the firm can be seen as a sub-economy. Traditionally, economists have argued that the provision of incentives is a core strength of competitive markets. Holmström, in contrast, argues that incentives are desirable in some situations, but counterproductive in others. In particular, in complex environments with information asymmetries excessively strong market incentives may undermine cooperation and/or induce cheating, manipulation or sabotage. To avoid these sideeffects of the market, it may therefore be advisable to pool ownership of all productive assets in a firm and to endow leaders (the management) with the power to define tasks and incentives. In this approach the firm is seen as a subeconomy in which the leader(s) take(s) over the role of the rule-setting government.

Recapitulating, this section has established that hierarchical leader-follower structures can be efficiency enhancing when markets fail to operate smoothly. However, in order for organizations to be successful, leaders need to play their role effectively. But what is effective leadership? It is important to understand that the meaning of effective leadership depends on the situation (House, 1996). In some cases, it may be sufficient if the leader monitors and sorts out misbehaving followers. In other cases, it is important that the leader succeeds in inducing cooperation and/or coordination among her followers. From an economic point of view, effective leadership requires that two conditions are satisfied: First, the right leader needs to be selected. Second, the selected leader needs to apply the leadership

\footnotetext{
${ }^{9}$ To improve readability we will from now on use the female form for leaders and the male form for followers and owners.
} 
strategy best adapted to the situation. In the next two sections of the paper we survey the economic literature on each of these two points separately.

\section{Leader Emergence: Who will be the leader? And will there be one?}

In this section, we explore how leaders emerge in different organizational circumstances. Our discussion builds on the economic perspective which focuses on incentives to lead and motives to appoint leaders. The view presented here is therefore quite different from the one that dominates the psychology and leadership literatures. Scholars studying leader emergence in those fields have mostly focused on the psychological traits of the individuals who emerge as leaders (see the so called 'trait theory'), and why these individuals are naturally followed by others (see the so-called ‘social cognitive theory’, see Eagly and Antonakis, 2015). These dimensions are, of course, also critical and important. However, we believe that a general theory of leader emergence ultimately requires that the two views become intertwined, so that the interplay between the situation and the person can be studied.

From an economist's point of view, a critical starting point for any discussion of leader emergence is an understanding of the ownership structure of the organization that needs leadership. ${ }^{10}$ Effective leadership requires the necessary degree of control over decisions within the organization, and control rights are importantly intertwined with ownership structures. We differentiate between leadership in organizations with and without clearly defined ownership structures. We begin by considering leader emergence in organizations with well defined ownership structures. Here, we will see that individual incentives and the owner's' ability to commit to non-interference are crucial determinants of leader emergence. Later on in the section, we turn to what we call "the leader emergence problem". In this part we discuss leader emergence when ownership is not well defined. We show that in those situations leadership can have the characteristics of a public good that no one wants to provide. Through game theoretic analysis, we highlight organizational characteristics that make this problem particularly severe and also discuss how organizations may overcome the problem, so that a leader emerges.

In an organization with a clearly defined ownership structure, control naturally rests with the owner. If there is a mismatch between those who might be best suited to lead and those who possess formal control (the owners), a challenge arises. The reason is that an appointed leader's decisions are always subject to interference from the owner.

\footnotetext{
${ }^{10}$ A related discussion on the interaction of formal control and leadership can be found in Bolton, Brunnermeier and Veldkamp (2013a).
} 
A recent example from the political sphere illustrates this problem: Germany’s economy minister Sigmar Gabriel gave ministerial approval for a merger between two supermarket chains in Germany. For this approval, he used his ministerial power and overruled the previous decision of the German federal cartel office to prohibit the deal. ${ }^{11}$ Whereas the federal cartel office argued based on antitrust considerations, the minister put more weight on supposed job losses in case the merger fails. As a consequence, the head of the German cartel office resigned. ${ }^{12}$

The example shows that a lack of formal control can prevent leaders from being effective. Anticipation of frequent overruling will naturally reduce a leader's ability and motivation to lead so that organizational inefficiencies emerge. Effective leadership therefore not only depends on individual characteristics and skills, but also on the institutional setup which must enable the potential leader to act independently. Appointing the right person to the leader position is not enough, because the person can only be effective if the position is equipped with the necessary decision power. The example also illustrates another important aspect of control in organizations: The decisions taken by the person in control are often discretionary in nature, implying that the controlling party can act, at least partially, in a selfserving manner, and its interests need not be perfectly aligned with the best interest of the organization. In the example above, the minister might have put more weight on personal political concerns, whereas the federal cartel office primarily decided based on potential welfare losses due to increased market power.

Does this imply that leaders always need formal control to be effective? The answer is no. Consider the example of university hiring decisions. In many universities, the hiring task is delegated to hiring committees, but final hiring decisions are taken by a dean or even higher up in some cases (e.g., the university president). However, these toplevel administrators rarely interfere with hiring committee decisions, and usually rubber stamp their proposals. Since hiring committees anticipate this behavior, they are effectively in control over hiring decisions and therefore committee members tend to be highly motivated.

Thus, although leadership naturally rests with the owners initially, it seems that owners can in some situations successfully transfer leadership to somebody else. But how and under what conditions can owners equip potential leaders with effective control? The easiest way to avoid the above discussed interference problem would be to directly contract control to the potential leader. However, for reasons that we discuss later, such a contracting solution is often

\footnotetext{
${ }^{11}$ http://www.reuters.com/article/us-germany-kaiser-s-idUSKCNOWJ20V

${ }^{12}$ https://global.handelsblatt.com/edition/392/ressort/companies-markets/article/watchdog-quits-amid-supermarket-takeover-row
} 
infeasible. In those cases, leadership may still be delegated if owners can commit not to interfere, as in the hiring example above. We will show later that such a commitment is possible if interfering is sufficiently costly to the owner (for example, because the owner needs to acquire new knowledge to be able to interfere). Finally, situations can arise in which no designated leader exists (including the owner), and someone needs to step up and take the lead, causing a problem of lacking leader emergence. ${ }^{13}$ The four different scenarios outlined above are displayed below in Figure 1. We will discuss them in more detail subsequently.

Figure 1: Scenarios of Leader Emergence

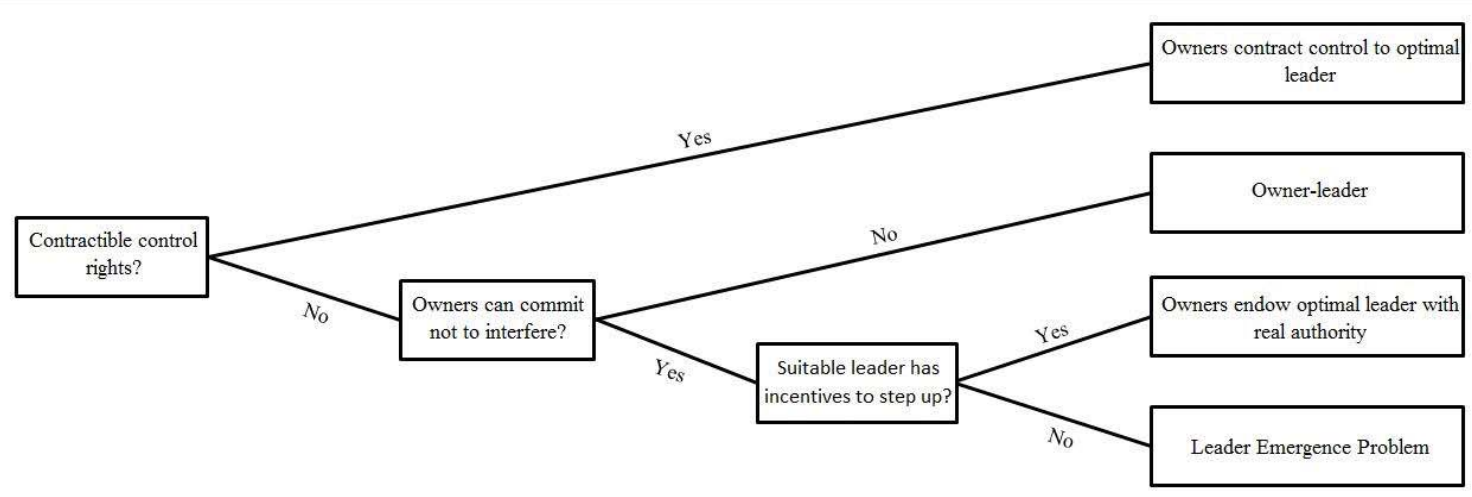

\section{Delegation of Formal Control Rights within Organizations}

Building on the property rights approach (Grossman and Hart 1986 and Hart and Moore 1990), Aghion and Tirole (1997) provide a comprehensive analysis of the optimal assignment of control rights within organizations. The initial owner of formal control faces a trade-off between two forces. By contracting formal control to a delegee, the owner relinquishes the possibility to choose the strategy that suits himself best. Instead, someone else will decide and may take discretionary decisions that partly serve self-interest, and might not be completely in the owner's best interest. This loss of control constitutes the cost of delegating formal control. The advantage, on the other hand, is that a leader who is equipped with formal control needs not fear interference by the owner. As a consequence, such a leader will be highly motivated to invest in effective leadership. If the appointed leader is better suited to lead a particular project than the owner (e.g., because of superior project specific knowledge or leadership abilities), the delegation of formal control rights can lead to better outcomes. Optimal assignment of control therefore needs to weigh off these two forces:

\footnotetext{
${ }^{13}$ Whereas we describe this problem as a leadership emergence problem within organizations with well specified ownership structures, the situation equally applies to leadership emergence in organizations without such clear ownership structures.
} 
In the presence of an alternative leader with superior leadership abilities and interests that are reasonably aligned with those of the owner, delegating formal control is likely to be optimal. Highly dissonant interests, in contrast, imply that it is typically better if the owner keeps formal control and leads himself.

This analysis implies that the optimal leader is only partially determined by personality characteristics that make individuals particularly suitable to lead. The personality traits interact in important ways with individual objectives and initial ownership structures. It is obvious that favorable leader attributes of a potential delegee make the formal transfer of control rights more attractive, simply because the leader will be more effective from the owner's perspective. But given the discretionary nature of control, owners will only part with it if they can be certain that their interests are sufficiently aligned with those of a potential alternative leader.

\section{Real Authority: Being a Leader without Having Formal Control Rights}

Leadership may be particularly valuable in unforeseen situations in which the survival of the firm is threatened and strategic decisions of great importance need to be taken. The problem is that in such situations it is impossible to empower a leader through the delegation of formal control rights, because this would essentially imply that the owner gives away his residual control rights (which would render the concept of ownership meaningless). Our discussion so far points to one supposedly optimal solution: Because a transfer of control rights requires a change of ownership, those most suitable to lead should ideally also own the organization. This way, the most effective leaders naturally possess the proper incentives to lead, and control and leadership are aligned. However, it is obvious that such an alignment of ownership and leadership is, in many cases, not feasible. A single owner may be completely overwhelmed with the multiplicity of decisions that have to be taken in different divisions of an organization. Similarly, leadership problems are idiosyncratic, and different individuals might be best suited to lead conditional on the leadership problem that arises. Or ownership may not be easily transferable, for example because of frictions in financial markets that do not allow the most capable leader to purchase sufficient stock to obtain ownership. ${ }^{14}$ Consequently, ownership and leadership will be separated in many relevant circumstances.

Aghion and Tirole (1997) argue that even if owners cannot delegate formal authority, they may still be able to equip a potential alternative leader with real authority in such circumstances. They distinguish real and formal authority as

\footnotetext{
${ }^{14}$ To alleviate this problem, CEO's and other top managers are often endowed and compensated with stock options, which help align, to a certain degree, the incentives of the leader and the overall organization.
} 
follows: formal authority refers to the formal right to take decisions, whereas real authority refers to the actual control over decisions. As Aghion and Tirole point out, actual control may reside with someone else than the owner if the owner can credibly commit not to interfere.

How can such commitment be achieved? In order to interfere, owners need to develop their own strategy, which may be costly and may take time. Owners will only undertake this effort if they face incentives that make it worthwhile. This, however, is often not the case because owners lack expertise and information with respect to the optimal strategy, or they work under permanent overload and time pressure, which makes it excessively expensive to engage in such developments. Or, if ownership is widely dispersed, which is usually the case in publicly held companies, each individual owner lacks the necessary incentives to make these investments himself. ${ }^{15}$ Consequently, in many situations owners can effectively tie their hands or signal their lack of competence regarding specific decisions, such that rubberstamping can rationally be expected. In these cases, the owner can credibly delegate real authority to another potential leader. ${ }^{16}$

Based on this analysis, we can reconsider the two examples at the beginning of this section: The university president can credibly commit not to interfere, because she typically lacks the subject specific knowledge (maybe except in her own faculty), has more pressing issues that she needs to attend to, and often has no reason to suspect that the recruiting faculty's interest are misaligned with her own. It is therefore rational for her to stay uninformed and rubber stamp the proposals submitted by the faculty. In the example of the dispute between the German minister and the cartel office, in contrast, credible commitment failed, because of misaligned interests between the two parties. In such situations the delegation of real authority is very difficult (or even impossible).

The Leader Emergence Problem: How to Find a Leader if Nobody Wants to Do It?

Organizations can also find themselves in situations in which neither the owners nor any of the suitable employees have the right incentives to take the lead. ${ }^{17}$ This is for instance the case in team sports if the team is losing badly and

\footnotetext{
${ }^{15}$ Note that the lack of monitoring incentives by owners in publicly held companies also implies that leaders may hold real authority despite quite substantial interest misalignment, such as in the case in which leaders use their real authority to extract substantial rents from the organization.

${ }^{16}$ Baker, Gibbons and Murphy (1999) show that commitment not to interfere can also credibly be established in a repeated relationship between the owner and the leader if interference would have negative consequences on the leader's future motivation.

${ }^{17}$ Such situations are usually not characterized as a problem of commitment. If they were, the owner would naturally emerge as the leader in the situation because he must have strong self-interests in the decision at hand. The owner can commit not to interfere but there is no candidate leader who naturally steps up.
} 
seems incapable of reacting, in public organizations such as hospitals when doctors/nurses face difficult situations with patients and one of them should step up to take a leadership role ${ }^{18}$, or even in partnership firms or firms with diffuse ownership facing difficult times. In all these cases, leadership is often badly needed and a great leader could emerge among the management team or the employees to enable the organization to stay afloat (Bass, 1995, Shadraconis, 2013), and to recreate a positive spirit and some consensus (Markoczy, 2003). However, despite the obvious need for a strong leader, its emergence is difficult to come about. Why can such situations arise?

In this subsection, we show that sometimes leader emergence can be similar to the provision of a public good. ${ }^{19}$ Everyone would benefit from strong leadership, but nobody is willing to pay the cost of being the leader. The problem is that the private costs of stepping up as a leader can be substantial. For many individuals, standing up, making charismatic speeches and pulling followers behind them requires great personal efforts, which need to be taken into account. Moreover, putting oneself in a leadership role creates a significant risk of failing, which may negatively affect future career prospects and may generate social pressure and public criticism. At the same time, the public good attributes of leadership can be substantial, because some of the benefits of leadership are non-excludable for all the employees, and also non-rivalrous. For example, recreating productivity through effective leadership does not reduce somebody's utility to the benefit of somebody else. This implies that the benefits are realized at the group level and benefit everybody involved, while the costs have to be carried by the individual leaders who step up. It can therefore easily happen that the individual benefits of leadership do not outweigh the private costs of leadership provision, so that nobody steps up to the occasion.

The game theoretic analysis in this section reveals that such leader emergence problems are more likely to arise when the costs of stepping up are particularly large. Somewhat surprisingly, larger attachment to the firm can effectively decrease the likelihood of leader emergence, because highly attached employees might have even more to lose from stepping up and have higher incentives to wait for others to do the job. Moreover, larger organizations may find it more difficult to see leaders emerge, despite the larger pool of potential leaders. To mitigate the leader emergence problem, organizations need to design private incentives that are not commonly shared, or they need to cushion the potential risks for those willing to step up.

\footnotetext{
${ }^{18}$ On this point, see for instance 'Doctors and nurses must step up to the plate to face NHS leadership crisis', October 19, 2015, www.Fieldfisher.com.

${ }^{19}$ A related theoretical framework has been proposed by Andreoni (2006) and further been developed in Hermalin (2013) in the context of charitable giving.
} 
To explore this situation in more detail, we consider a simple public goods game similar to the one proposed by Blomberg et al. (2009). The game is played only one time and simultaneously by $n$ players (the organization's owners and employees), in which each owner and employee ${ }^{20}$ has to decide whether or not to step up, make an inspirational speech and take a leadership role. Everyone receives a benefit $B$ if the organization is saved. $B$ captures all potential individual benefits if the organization succeeds, including the personal attachment — that is psychological benefits — they might have with the organization. ${ }^{21}$ However, employees also face a cost $\alpha B$ for stepping up as a leader. On one hand, these costs capture the cost of effort an employee has to undertake to stand up and take a leadership role. On the other hand, they capture the economic and social risks associated with the leadership role -that is, the employee might just fail and get laid off, or might suffer unexpected reactions from his colleagues such as jealousy or many negative feelings by distancing himself from the group. Since the latter costs are higher the more an employee would like to continue working for the organization, the individual cost of stepping up as a leader depends on $B$.

If no employee decides to provide leadership then everyone among the $n$ employees suffers a cost $\beta B$. The parameter $\beta$ characterizes the cost of inaction, which depends on the severity of the crisis as well as the outside options available to employees: for instance, this cost will be lower in countries with low unemployment, a well-functioning labor market or if the firm operates in a growing sector. We assume that $1 \geq<\geq ® \geq 0$. This assumption guarantees that the individual costs of stepping up as a leader are significant for the employees of the firm, which is the core of the problem we are trying to capture here.

The expected utility for each employee in case no one emerges as a leader is then $B-\beta B$, while the expected utility for the one who steps up is $B-\alpha B$. The first implication of this game is that the unique equilibrium solution is the situation in which none of the players will decide to move: because $B-\alpha B<B-\beta B<B$, employees will have no individual incentives to stand up and no leader will emerge. The crisis situation will keep developing within the organization, and the sum of the utilities of the $n$ employees will be $n(B-\beta B)$. This sum characterizes the overall welfare implication of the game. Note that, collectively, this outcome is inferior to a situation in which one employee would have the courage to step up as a leader (whose welfare implication would be $(n-1) B+B-\alpha B$ ) as soon as $\alpha<$

\footnotetext{
${ }^{20}$ We make no difference here between owners and employees, and just assume that in a crisis situation all face similar costs and benefits to stand up, provide their vision and try to emerge as one of the new leaders of the organization.

${ }^{21}$ Of course, we are aware that taking on leadership also creates some personal benefits in most cases. These benefits may include such diverse things as the satisfaction of a need to have an impact or to have power, reputational benefits, status effects etc. However, in this part we are interested in situations in which these personal benefits are small relative to the cost. For simplicity, we therefore neglect them in the analysis.
} 
$n \beta$. Because this is always so in cases of interest for leadership -otherwise, the cost of inaction for all employees would have to be really low, and hence the need for leadership would basically be absent- this situation rightly characterizes the leader emergence problem in which no suitable leader has incentives to step up. Given the public good nature of the problem, all employees would be better-off if someone would emerge as a leader, but no one has the individual incentives to do so.

How can owners overcome the leader emergence problem in such situations? In order to induce someone to step up, some additional specific incentive must be designed to make leadership emergence possible. We denote this additional incentive as a bonus $L \geq 0$ for the employee who will decide to take the leadership role, for instance through a better job in the newly saved company and/or a higher salary when the crisis is finished. We assume that this bonus is decided by the owners supervising the organization and communicated, either formally or informally, to the employees. A pay-off matrix for this game, for simplicity limited to 2 players ( $i$ and $j$ ), might therefore be written as follows:

Table 1: Leadership emergence: a payoff matrix

\begin{tabular}{|c|c|c|}
\hline Employee i / Employee $\mathrm{j}$ & Stepping up as a leader & No move \\
\hline Stepping up as a leader & $B-\alpha B+L, B-\alpha B+L$ & $B-\alpha B+L, B$ \\
\hline No move & $B, B-\alpha B+L$ & $B-\beta B, B-\beta B$ \\
\hline
\end{tabular}

It is now easy to see that the condition for a leader to emerge is that $L \geq B(\langle-\AA)$. If this condition is violated, the bonus would not be enough to generate leadership emergence. Note that one implication of this analysis is that the reward for stepping up as a leader will have to increase as the individual cost of leadership $(\alpha)$ increases, a result that is fairly intuitive, and as the utility for the employees of the organization staying alive $(B)$ increases. The latter result on $B$ is interesting as $B$ highly depends on the employees' attachment to the organization. In other words, and somewhat counter-intuitively, a higher bonus needs to be transferred to employees to create incentives for leadership when employees are deeply attached to the organization and would really like it to survive. Alternatively, firms may want to lower the cost of leadership associated with the threat of failing and being fired by offering those who step up a guarantee to return to their old job as a worst case scenario. 
On the other hand, the necessary reward $L$ becomes lower as the cost of inaction $(\beta)$ increases. If employees expect to have a very hard time finding a new job, for instance, one of them is more likely to make the effort and take the risk to position herself as a new leader. This result is again quite intuitive but also certainly interesting as it allows for comparisons across regional areas, countries or even industrial sectors. Leader emergence will require a lower leadership reward in places or sectors where labor markets are less dynamic.

From the perspective of the organization and of the employees collectively, it can be seen that the optimal number of leaders that should emerge is only one. Here, it is important to note that the bonus $L$ constitutes a transfer from the owners or from other employees, and hence can be neglected in an analysis of total welfare. If at least somebody steps up and the number of employees who do is $j$, with $1 \leq j \leq n$, the total welfare implication is $(n-j) B+j(B-\alpha B)$. A solution with no leader is therefore inferior to a situation with one leader since $n(B-\beta B)<n B-\alpha B$, but also a solution with two leaders would be inferior to one with one leader since $n B-\alpha B>n B-2 \alpha B$. If more leaders step up there are additional costs, but no additional benefits.

To go further, one can determine the probability that at least one employee emerges as a leader. This analysis starts by looking at the conditions under which an employee will be indifferent between stepping up as a leader and hiding within the group. This depends on the probability with which each individual employee is willing to step up. If $p$ is that probability, this translates into the following equilibrium condition:

$$
B-\alpha B+L=(B-\beta B)(1-p)^{n-1}+B\left(1-\left(1-p^{n-1}\right)\right.
$$

Simplifying and solving for $p$, one obtains:

$$
p^{*}=1-\left((\alpha B-L) / \beta B^{1 /(n-1)}\right.
$$

Given that each employee steps up with probability $p^{*}$, the probability that at least one employee steps up is given by $P^{*}=1-\left(1-p^{*}\right)^{n}$. Following our analysis above, this confirms that the probability that at least one leader emerges decreases with the individual costs of stepping up as a leader $(\alpha)$ and with the value attributed by the employees of the firm staying in business $(B)$. Conversely, an increase in the bonus $(L)$ and in the cost of inaction $(\beta)$ increases the probability of leader emergence. Again, this confirms previous analysis. The most interesting new insight, however, relates to the size of the organization (through the number of employees, $n$ ). Looking at the derivative of $P^{*}$ with respect to $n$, an increase in $n$ can reduce the probability of leadership emergence. It is an interesting and non-obvious result since firm size could intuitively increase or decrease the probability of leader emergence. Larger firms count 
more people who can become leaders but also suffer from larger coordination problems among employees; it is those coordination problems that can prevail, making it more difficult to get leaders to emerge.

\section{Novel Avenues: Interactions of Incentives and Personality Traits}

Our previous analysis has shown that whether a particular person can and will emergence as a leader depends on both, organizational constraints and individual incentives to lead. Up to this point, we have been relatively agnostic about the origin of individuals' incentives to become a leader. Incentives to lead can be manifold, including private financial benefits, bonuses and other rewards provided by the owners, career concerns, or empire building (Niskanen, 1971), but also psychological factors such as a need for power (McClelland, 1975).

From an organizational point of view, however, it is not only important that some leader emerges, but even more so that the emerging leader is the most suitable person. Who is most desirable as a leader depends on the particular situation at hand. If a team needs to complete a particularly complex task, the optimal leader might be the most knowledgeable expert, if instead the aim is to motivate a group of workers for an event, it might be best to pick the most charismatic presenter as the leader. Other situation-specific characteristics of effective leaders that have been identified in the economics literature are, for example, good communication skills and a long-run horizon (Rotemberg and Saloner, 1993), vision and conviction (Rotemberg and Saloner, 2000), confidence (van den Steen, 2005, 2010) or even overconfidence (Gervais and Goldstein, 2007; Blanes i Vidal and Möller, 2007), and being a team player (Bolton et. al. 2013a).

It is therefore of crucial importance to reflect on how an organization can achieve that the right person emerges as the leader. We have seen that if an owner can contract control or commit not to interfere, he indeed can choose the most suitable leader (conditional on interest alignment with the owner). However, if ownership is less clearly defined and a leader needs to step up endogenously, leader emergence is solely driven by the individual incentives that the potential leaders face. The problem is that those personality characteristics that have been identified with good leadership (vision, charisma, confidence etc.) are not necessarily identical with those that induce people to step up (such as need for power or career concerns). Coffman (2014) provides an illustrative example for the mismatch between desired characteristics and characteristics of people who step up. She finds that women (men) are less likely to emerge as leaders if a problem is male-stereotyped (female-stereotyped). As a consequence, group performance suffers, because the most talented members lack sufficient influence. It is therefore important not only to understand the incentives 
that induce potential leaders to step up and to know the personality characteristics that define great leaders, but also to make sure that the institutional arrangements induces the right leaders to emerge.

In the model discussed in the previous section, emergence can be affected through the individual bonus $L$ that the emerging leader receives. This bonus could, among other things, take the form of a financial reward, an office, or a discretionary budget, but could also consist of non-pecuniary perks and status, or a symbolic award (Kosfeld and Neckermann, 2011). ${ }^{22}$ As a function of what is offered, different people will step up, depending on their individual preferences and motives. Future research needs to systematically study how different types of incentives interact with personality, and how they shape the motivation of heterogeneous leader types. Understanding these interactions is important to be able to design appropriate institutions and bonus structures such that the right person will emerge conditional on the leadership problem.

Another interesting and important facet of the emergence problem is that it exists on multiple levels within an organization. So far, we have focused on the problem of assigning control rights from the perspective of an owner who needs to ensure effective leadership. In reality, however, the leader herself is often also severely time and capacity constrained such that she herself needs to delegate control to subordinates for specific projects. Bolton et. al. (2013a) emphasize this point and refer to empowering others as one key element of effective leadership. The previously described problem therefore is not only relevant for owners but also for leaders at all levels of the hierarchy: optimal delegation is a crucial task that effective leaders need to carry out.

Unfortunately, however, there seem to be psychological mechanisms that render effective delegation difficult for many decision makers. In a laboratory experiment, Fehr, Herz and Wilkening (2013) have shown that people tend to be reluctant to give up decision rights, even if delegation is optimal from an organizational point of view, and often also in terms of own material well-being. In their most striking example, Fehr, Herz and Wilkening (2013) show that more than half of their participants are unwilling to delegate control to a subordinate even if doing so is profitable given what the participants themselves believe, increases own profits by $45 \%$ in the actual data, and increases overall profits for the organization by $30 \%$ in the actual data. ${ }^{23}$ Bartling, Fehr and Herz (2014) show that such behavior may be linked to an intrinsic preference for control. Consequently, while it is important for effective leaders to be equipped with the

\footnotetext{
22 The literature on extrinsic and intrinsic motivation (Deci and Ryan, 1975) clearly indicates that individuals are indeed not only motivated by extrinsic rewards.

${ }^{23}$ Relatedly, Danz et. al (2015) show that hindsight bias interferes with optimal delegation.
} 
necessary control rights, another important characteristic of an effective leader is her ability to delegate decision rights to subordinates herself. It seems important to explore further how the personality traits underlying this phenomenon interact with leader emergence.

\section{Leader Effectiveness: What should leaders do?}

It is not easy to define what leaders should do. The responsibilities of a leader are manifold and often specific to the environment. Leaders select and control their followers (hiring, firing, monitoring), they serve as judges in internal conflicts, they provide followers with information (sharing expertise), and they often serve as symbols for the group they lead. However, despite the obvious complexity of the leader role and the lack of a unified definition of what leadership exactly constitutes, most leadership researchers would probably agree that in many cases the leader's predominant task is to influence her followers to act in the interest of the organization or group for which she is responsible (Bass, 1990 and House et al., 1999). This view is also in line with the theories discussed in our section on the foundations of leadership. Different approaches discussed there vary in how they justify the need for leadership, but all theories classify the enhancement of cooperation and coordination as a crucial task of the leader.

Whereas leadership scholars and economists mostly agree on the aims of leadership, they have focused on very different methods to achieve these aims. When economists think about the motivation problem, they typically consider a contracting solution. A central idea in the economic approach is that a leader can create incentives for followers to act in the interest of the organization by linking followers' payoffs (compensation, perks, promotions etc.) to their performance (see Gibbons and Roberts, 2013, for a recent survey of the principal-agent literature). This type of leadership corresponds to the "contingent reward" dimension of what Burns (1978) and Bass (1985) called transactional leadership. Economists have developed a nuanced understanding of the impact of (different types of) incentive schemes on follower performance in a broad variety of situations, but they have largely ignored that leaders may also have other (often softer) channels through which they can influence followers' behavior.

In the leadership literature, in contrast, the situation is almost reversed. Purely transactional leadership is regarded as basic and rather unimportant. Instead, proponents of transformational leadership and related theories (e.g., charismatic, visionary, or inspirational approaches) emphasize that effective leaders should not only rely on rewards and sanctions, but should also make use of their personal abilities to persuade and motivate (see, for example, House, 1977, Bass, 1998, 1999 and Howell and Avolio 1993). The idea is that transformational leaders provide followers with a common mission and vision and give them a sense of identity (Shamir et al., 1993). 
We argue that both views are too narrow. It is neither justified to fully concentrate on contractual solutions, nor is it advisable to underrate the power of incentives and to put too much weight on non-transactional leadership styles. In this section we illustrate how the economic framework allows distinguishing environments in which purely transactional types of leadership will suffice from those in which other leadership styles, such as transformational, charismatic or inspirational leadership, are needed. We will argue that leadership scholars can benefit from taking into account the insights that economists have established for contractual solutions in those situations in which incentives are likely to work well. At the same time we also highlight the limits of the transactional approach and provide an outlook on how economists can benefit from enriching their framework with the rich insights on transformational tactics that leadership research in management and psychology has generated over the years. ${ }^{24}$

Our analysis permits us to draw a simple "map" that provides guidance for how the characteristics of the environment affect the leader's optimal choice of style (see Figure 2).

Figure 2: Environmental Characteristics and Leadership Style

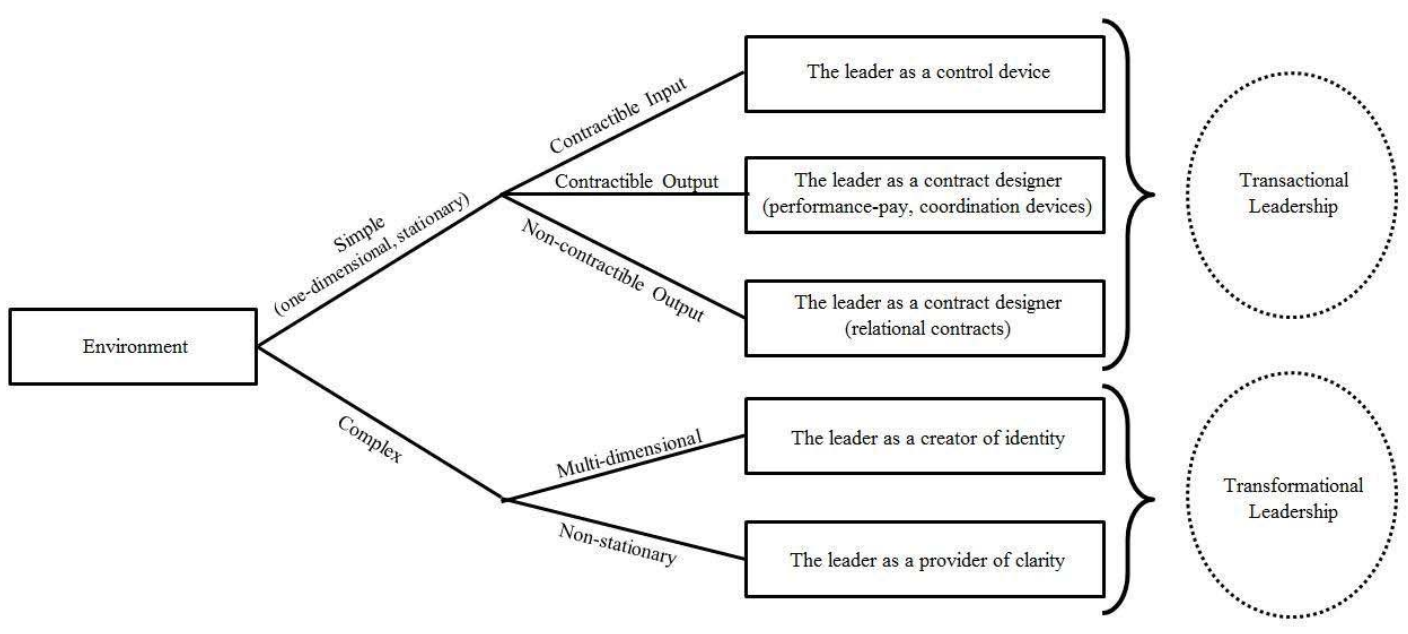

The figure identifies environmental complexity as the most important determinant of leadership style: the simpler the environment, the easier it is to lead with transactional tools. In very basic environments, in which individual follower input is observable and verifiable, the leader can simply enforce a contract that specifies the followers' obligations

\footnotetext{
${ }^{24}$ Whereas the main focus of this section will be on the transactional-transformational dichotomy, we will also directly relate to leadership by expertise which is part of instrumental leadership (Antonakis and House, 2014, Goodall and Pogrebna, 2015).
} 
(contractible input). In this case it suffices if the leader acts as a control device and removes or sanctions underperforming followers. In most situations, however, the leader observes followers' outputs rather than inputs. If output can be verified so that a court can enforce output-based contracts, leaders can rely on explicit performance pay (contractible output). Principal-agent theory predicts that such incentive contracts work well, as long as tasks remain simple (one-dimensional) and measured output cannot easily be manipulated. However, even if output is only observable to the leader and the follower, but not to outsiders like the courts (non-contractible output), leaders may still be able to use contracts. As long as the environment is (approximately) stationary (i.e. stable over time), leaders can replace legally enforceable, formal contracts with informal, relational contracts that are enforced through reputational concerns within repeated interactions.

Transactional methods reach their limit when the environment becomes complex. In particular, we emphasize two different types of complexity that both call for transformational leadership tactics. The first one is multidimensionality. If followers' tasks are manifold, proper incentivization requires that all tasks that are important to the leader are compensated equally. In practice, this is difficult to implement so that complex jobs are rarely managed through explicit contracts. In those cases, the lack of extrinsic rewards must be compensated with intrinsic motivation. This requires transformational leaders who succeed in creating a common mission and induce followers to identify with the cause they work for. The second important type of complexity is non-stationarity. This corresponds to situations in which the environment is subject to constant change and there is a lot of uncertainty about the future. Non-stationarity makes it difficult to sustain relational contracts, because there is the permanent risk that environmental shocks trigger misunderstandings which threaten the relationship. In those situations it is of great value if there is a transformational leader who is able to increase clarity by creating a shared vision and by establishing a set of general principles that provide guidance to followers.

In general, the figure illustrates an important point: despite obvious limitations, transactional leadership can be an effective motivation and coordination device in a broad set of environments. Contractual solutions tend to be simple and relatively inexpensive, because the leader "only" needs to align followers' payoffs and beliefs. Transformational interventions, in contrast, require substantial investments, because the leader needs to influence followers' preferences by creating common visions or even a shared identity. Since transformational leaders are a scarce resource, it is important that their skills and talents are used in those cases where they are most needed. 
The remainder of this section covers the message transported by Figure 2 in more detail. We first illustrate why incentives are powerful motivators in relatively simple environments, but tend to fail in complex situations. Subsequently, we outline how future research can broaden the scope of the economic paradigm by integrating insights from research on transformational leadership. Second, we explore the leader's influence on follower coordination. We review the existing economics literature and show how leaders can shape followers' beliefs to make them coordinate on efficient outcomes. Finally, we point out why non-stationary, dynamic environments may require transformational interventions to create the required clarity in beliefs necessary for efficient collaboration.

\section{The Motivation Problem}

\section{$\underline{\text { Performance Pay in Simple Environment }}$}

In this section we discuss how leaders can design payoff schemes to motivate followers to act in the interest of the organization (Jensen and Meckling, 1976, Hart and Holmström, 1987, Holmström and Milgrom 1987). Given that the contractual solution is trivial if the leader can directly contract on inputs (see the top box in Figure 2), we focus on the more interesting case in which the leader observes output rather than input (the second box from the top in Figure 2). In the most simple case, a risk-neutral leader wants to induce a risk-averse follower to engage in a simple, onedimensional activity $a .^{25}$ Activity $a$ is not observable, but the leader observes the produced output $y$, which consists of a combination of the follower's input $a$ and outside influences $x$ that are not under the follower's control: $y(a)=a+$ $x$. For simplicity, the outside influences are assumed to be a normally distributed random variable with a mean of zero and a positive variance : $x \sim N(0$, ). Performing the activity has an increasing and convex cost $c(a)$ for the follower. The leader offers a contract of the form: $w=s+b y$, so that the follower's compensation $w$ is a combination of a fixed payment $s$ and a performance-dependent part by. The factor $b$ measures the intensity of incentives. ${ }^{26}$ In such an environment a profit-maximizing leader chooses the optimal incentive intensity $b^{*}$ according to the following formula:

The mathematical details are of little importance in this context, but the interpretation of the formula is instructive. The optimal incentive intensity $b^{*}$ is high if the impact of outside factors on output is limited ( is low), the worker is

\footnotetext{
${ }^{25}$ The justification for the assumption that the leader is risk-neutral, while the agent is risk-averse is that the leader typically has many followers so that his risk is broadly diversified. For simplicity, we assume that the agent's utility function exhibits constant degree of absolute risk aversion denoted by the Arrow-Pratt measure $r$.

${ }^{26}$ It is easiest to think of $b$ as a piece rate or commission, but the model also applies to other forms of financial incentives.
} 
not very risk averse ( $r$ is low), the worker has the required ability to respond to incentives $\left(c{ }^{\prime \prime}(a)\right.$ is low), and the firm's revenue strongly depends on followers' engagement $\left(y^{\prime}(a)\right.$ is high).

Empirical work in personnel economics offers strong support for the hypothesis that simple transactional pay-forperformance schemes work well when the task is simple and the worker has a lot of control over his output. It has, for example, been shown that piece rate contracts and commissions have large positive effects on work performance for windshield installers (Lazear, 2000), tree planters (Shearer, 1999, 2004), fruit pickers (Bandiera et al., 2005) and bike messengers (Fehr and Goette, 2007). In addition, the theory also implies that the implementation of performance-pay schemes leads to important selection effects. In particular, explicit incentive contracts should be especially attractive for highly productive workers with low risk aversion. Also this prediction has received empirical support both in the field (Lazear, 2000) and in the laboratory (Dohmen and Falk, 2011).

If output is a poor proxy for effort (is high), high-powered individual incentives are not advisable, because excessively high payments are required to compensate followers for the income risk imposed on them. In some cases, leaders can circumvent this problem by paying for relative performance instead of absolute output (Lazear and Rosen, 1981, Holmström, 1982). This solution makes sense if it is difficult to measure individual contributions in absolute terms, but easy to tell who performed better or worse than others. However, relative performance pay schemes entail the danger of inducing counterproductive behaviors such as collusion, denial of collaboration or even active sabotage (Gibbons and Murphy, 1990, Murphy, 1999). ${ }^{27}$

\section{$\underline{\text { The Curse of Complexity }}$}

The basic model is restricted to one-dimensional tasks and does not apply when followers need to devote their time to a variety of activities. We now consider situations in which each follower performs multiple tasks (Milgrom and Holmström, 1991, 1994). To keep the notation simple, assume that the followers can engage in two non-observable activities $a_{1}$ and $a_{2}$ (adding more activities would be straightforward). Each activity generates an observable suboutput, which is (as before) determined by a combination of the activity itself and outside influences: $y_{1}=a_{1}+x_{1}$ and $y_{2}=a_{2}+x_{2}$, where $x_{1}$ and $x_{2}$ are independently and normally distributed random variables with a mean of zero and potentially different variances and . Suppose that performing either task is equally hard for the follower so that his cost is only determined by the sum of efforts invested in both activities: $c\left(a_{1}+a_{2}\right)$. The two sub-outputs are only useful

\footnotetext{
${ }^{27}$ One wide-spread form of relative performance pay is promotion tournaments. See Lazear and Oyer (2004) and Waldman (2004) for coverage of recent work on tournaments.
} 
together, so that a follower's total output is equal to the minimum output produced with either one of the two activities: $y\left(a_{1}, a_{2}\right)=\min \left(y_{1}, y_{2}\right) \cdot{ }^{28}$ The leader offers a contract with a payment scheme of the following form: $w=s+b_{1} y_{1}+b_{2} y_{2}$. i.e., in addition to the fixed pay s there are variable payments which are contingent on the two sub-outputs. Because the follower is indifferent between the two tasks, it is easy to see that he would focus on the task which generates higher returns for him. Thus, if $b_{1}$ is larger than $b_{2}$, the follower would get fully engaged in $a_{1}$ and would neglect $a_{2}$ (and vice-versa). This implies the so-called "equal compensation principle": if the leader wants to make sure that the follower devotes effort to all activities, each relevant activity needs to provide the same marginal rate of return to the follower: $b_{1}=b_{2}$.

The equal compensation principle imposes important constraints on the use of incentives in practice. If all relevant activities are relatively easy to measure (i.e., and are of similar size and small), things are simple and the leader just needs to make sure that incentives are balanced across tasks. In most cases, however, the situation is more complicated in reality. Assume, for example, that one of the activities is easily observable ( is relatively low), while the other one is very hard to measure (). An illustrative example is school teaching. Suppose that the school board wants the teachers to put emphasis on both teaching formal skills to the students $\left(a_{1}\right)$ and improving their social skills $\left(a_{2}\right)$. Success in teaching formal skills is relatively easy to measure using standardized tests, doing the same thing for advancements in social skills is quite difficult. The principles derived for the simple, one-dimensional model above imply that it would be desirable to set a high incentive for the easily measurable activity $a_{1}$ and flat incentives for the hard to observe activity $a_{2}$. However, such a scheme would obviously violate the equal compensation principle and would imply that teachers fully focus on teaching formal skills and would completely neglect the social education of their students. So, what should the school board do? Well, given that the difficulty of measuring the teacher's success in fostering social skills prevents the board from using incentives in that dimension, they should also refrain from incentivizing the teaching of formal skills. In other words, they should not use incentives at all and pay the teachers a flat salary $\left(b_{1}=b_{2}=0\right)$. In this case, teachers are only induced to perform through their intrinsic motivation. This "multi-tasking" problem is one of the most important limitations of explicit performance pay: the compensation of complex jobs can often not be done through explicit contracts (Prendergast, 1999).

\footnotetext{
${ }^{28}$ The minimum function is an extreme assumption that implies perfect complements. We make this assumption for simplicity. Similar results apply as long as there is a certain degree of complementarity (sub-outputs cannot be perfect substitutes).
} 
Another closely related problem is the "manipulation of performance measures" (Baker, 1992, Feltham and Xie, 1994). This time assume that the leader cannot directly observe the output $y$ produced by the follower, but she can only see a proxy for output $z$. Output is determined by a particular activity $a_{1}$ (plus the usual outside influences): $y\left(a_{1}\right)$ $=a_{1}+x_{y}$. However, the proxy for output is affected by two activities, the same activity $a_{1}$ that also determines output, but also another activity $a_{2}$, which has no impact on output: $z\left(a_{1}, a_{2}\right)=a_{1}+a_{2}+x_{z}$. Because the leader cannot observe output $y$, any incentive contract needs to be based on the observed proxy $z: w=s+b z$. It is easiest to think of activity $a_{1}$ as real work and to consider activity $a_{2}$ as cheating behavior. Cheating is potentially attractive to followers, because it increases the output measure $z$ and therewith their compensation, but effort spent on cheating does not affect actual output and is therefore a complete waste of resources. Suppose that each activity is costly to the follower, but this time the costs of the two activities are assumed to be separable $\left(c\left(a_{1}, a_{2}\right)=c\left(a_{1}\right)+c\left(a_{2}\right)\right)$ and their levels may differ: $c\left(a_{2}\right)$ $=m \times c\left(a_{1}\right)$, where $m$ is a scaling factor. The leader's problem in this situation is that incentives not only increase the follower's engagement in work $\left(a_{1}\right)$, but always also induce cheating $\left(a_{2}\right)$. The severity of this problem is determined by the scaling factor $m$ : the smaller $m$, the cheaper and more attractive it is to cheat for the followers. If $m$ gets very small, incentives induce mostly cheating and have a comparatively low impact on work. In such cases, the leader may be better off by relying on flat wages. By doing so, she fully relies on followers' intrinsic motivation, but at least they do not have incentives to engage in cheating activities. Extended versions of this model endogenize the cost of cheating. This leads to an interesting new trade-off where the leader might be willing to make costly investments in order to increase $m$, because this allows her to benefit from using higher-powered incentives.

Anecdotal evidence for misbehavior triggered by incentive pay is easy to find. A recent well-fitting example is the following one: in 2011 the management of a large Swiss supermarket chain decided to install a new incentive scheme to increase the profits generated by the butcheries in their stores. The aim was presumably that the butchers improve their sales activities, optimize the fit between what customers demand and what they offer and cut down costs by optimizing processes. While it may well be true that some of the intended goals were reached, butchers also started to systematically unpack meat that was close to the expiration date and put it in the open counter to be able to sell it beyond the date printed on the package. When (former) employees leaked this practice to the press, the incident lead to a nation-wide scandal. ${ }^{29}$ Other well-known examples include the manipulation of accounting numbers to optimize sales figures in a particular, bonus-relevant period (Goodpaster and Post, 1981), the increase of commissions by

\footnotetext{
${ }^{29}$ http://www.swissinfo.ch/eng/customers-deceived-in-expired-meat-scandal/31536360
} 
fraudulently overstating past usage to trick customers into buying larger subscriptions (Roberts, 1989), the misleading of customers into authorizing unnecessary car repairs (Patterson, 1992), or the manipulation of student's test grades by incentivized school teachers (Jacob and Levitt, 2003). All these activities had severely negative consequences for the companies involved and some of them resulted in millions of dollars in lawsuits.

\section{Novel Avenues: Leaders as Creators of Identity}

Our review of the principal-agent literature has revealed that transactional leadership tools such as monetary incentives and direct control can have large positive effects on follower motivation in simple environments. In more complex environments, in contrast, there is the danger that incentives have unwanted or distortive implications. So an important question is: what should leaders do when incentives don't work?

The leadership literature in management and psychology provides a possible answer. Research on transformational leadership and related approaches (e.g., charismatic, visionary, or inspirational leadership) suggests that effective leaders can go beyond transactional measures, and shape their followers' behavior also through their personal abilities to persuade and motivate (see, for example, House, 1977). Transformational leaders inspire their followers by providing them with a common mission and vision and by giving them a sense of identity (Shamir et al., 1993). Ideally, we would be able to integrate this view into the economic framework. Such a synthesis might allow us to build models that provide a much richer and more in-depth understanding of the interplay of environment, leadership styles and leader effectiveness.

So far, economists have largely ignored transformational and other non-transactional leadership tactics. The reason is that from an economist's point of view, the transformational approach seems to require that the leader is able to control (or at least to affect) her followers preferences. The idea that preferences are endogenous and may even be influenced by other human beings is in strong contrast to the conventional assumption that people's tastes are exogenously given and remain unchanged. However, recently influential economists have started challenging the traditional view. Most relevant for our topic, Akerlof and Kranton (2000, 2005, 2010) propose that individuals' preferences should not be modeled as exogenously fixed, but should be allowed to vary with social context. ${ }^{30}$ In a novel approach termed identity economics they push the notion that people derive utility from having an identity. They define identity as the social categories a person belongs to. According to this theory, people not only care about outcomes per se, but they are also

\footnotetext{
${ }^{30}$ Hermalin (2013) also mentions the possibility that the leader can be a "shaper of preferences", but the notion is not further developed in the models discussed in his review.
} 
concerned about the extent to which these outcomes are compatible with social norms they identify with. ${ }^{31}$ To the extent that leaders can affect the emergence and persistence of social norms within the groups they lead, this theory provides the leader with a natural role as a shaper of identities.

A leading example in Akerlof and Kranton's work is the military. One of the things that military leaders try to achieve from the get-go when new recruits arrive is the creation of a strong in-group feeling. Soldiers all get the same haircut, they wear the same clothes (uniforms) and they are quickly introduced to a number of specific rituals (saluting, springing to attention, military language). All these measures help to impart an identity. The soldiers start to become a unit and they identify with the goals of the armed forces. Interestingly, explicit pay-for-performance contracts are almost completely absent in the military. Ranks and pay are predominantly determined by seniority and exceptional achievements are typically rewarded with medals instead of bonuses. Soldiers are motivated, because their actions are guided by salient and powerful social norms (following orders, service before self, etc.). The creation of identity creates the intrinsic motivation necessary to compensate the lack of extrinsic motivators. Instead of working hard to increase their income or other material benefits, soldiers exert a lot of effort, because they think it is the right thing to do. Not doing so would violate social norms they believe in, and as a consequence they would lose identity utility. The military is a prototypical example, because it has a number of characteristics which make it ideal for transformational leadership. First, individual contributions are hard to measure (especially in battle situations). This makes it difficult to rely on transactional tools. Second, soldiers often self-select into the armed forces, that is, many of them already identify with the goals of the military when they arrive. This facilitates the creation of a shared identity. However, it is obvious that the same approach can also be used in many civilian contexts. ${ }^{32}$ In general, the theory distinguishes between two types of followers: outsiders and insiders. Outsiders are people who are mostly concerned with themselves. They lack intrinsic motivation and are willing to work hard only if they face strong extrinsic incentives. Insiders, in contrast, identify with the organization they work for and incorporate the organization's goals (Elsbach and Kramer, 1996; Gioia and Thomas, 1996). They feel an urge to work on behalf of the organization and lose identity utility if they deviate from their group's social norm to put in high effort. The leader's challenge is that all (or at least most) followers are outsiders in the beginning. It is important to realize that turning outsiders into

\footnotetext{
${ }^{31}$ Akerlof and Kranton's approach can be seen as a special case of the concept of reference-dependent preferences, see Kahneman and Tversky, 1979, 1992, Köszegi and Rabin 2006.

${ }^{32}$ For example, the fact that employees at google refer to themselves as "Googlers" is a strong indication for joint identity.
} 
insiders is, in most situations, not an easy task. Making the transformation happen typically requires considerable investments (training, establishment of rituals, standards and norms etc.). Whether or not it is worthwhile to undertake these investments depends on the situation-specific nature and size of the required investments and on the effectiveness of alternatives, in particular transactional leadership.

Economists know very little about the details of transformational leadership. In which organizational contexts does it work best (Judge and Piccolo, 2004)? What are the strategies that leaders can use to complete this process and how does the effectiveness of these different strategies depend on the environment (Waldman et al., 2001)? Which type of interventions work best (Avolio et al., 2009)? These are questions that leadership scholars have begun to investigate. Future economic models of leadership need to integrate and formalize these insights. Doing so will lead to a richer and more detailed understanding of the trade-offs involved in the choice of the efficient leadership style.

\section{The Coordination Problem}

\section{$\underline{\text { Coordinating Beliefs in Static Environments }}$}

An additional channel through which leaders can affect follower motivation and organizational efficiency is through their impact on follower beliefs. This channel can be particularly decisive in situations in which the performance of an organization depends on whether its members succeed in coordinating on a common strategy. Such coordination is, for example, necessary if team members, or different company divisions, have to provide complementary actions that jointly determine overall success. In such situations, high effort by one team member will only lead to success if it is met by high effort of the other team members as well. For instance, one line of erroneous code written by a single programmer within a programming team may be sufficient to render the software dysfunctional. Information asymmetries imply that simple contracting solutions are typically not feasible for such problems. Beliefs about the effort and quality of work of co-workers become therefore decisive determinants of each worker's incentives to work hard. ${ }^{33}$ The problem is that workers who believe that their co-workers will fail to work hard will slack as well, not because they are not motivated, but because they anticipate that low contribution of the others would render their hard work pointless. Coordination on weak effort can arise easily, because it can be triggered by so called "higher order beliefs". To illustrate this point assume that all workers in a group are highly motivated and eager to put in hard work. However, everyone believes that there is at least one worker who believes that another worker has doubts about the

\footnotetext{
${ }^{33}$ A related problem is one in which divisions of a firm need to coordinate on an efficient plan of action, and only coordinated actions lead to overall success. Here, inefficiencies may arise not because of potential demotivation due to wrong beliefs but because uncoordinated strategies are chosen that are incongruent with each other.
} 
motivation of some of his colleagues. This structure of beliefs leads to a complete breakdown. Moreover, it is difficult to get out of this situation, because the beliefs are self-confirming, in the sense that observed behavior in the group is in line with the initial beliefs (although the initial beliefs themselves may not have been accurate). In such situations, it is therefore particularly important that a leader manages and aligns beliefs. If the leader manages to establish common knowledge that everybody is motivated, the breakdown can be avoided and an efficient outcome is possible. ${ }^{34}$ The multiplicity of equilibria turns coordination games into a very interesting object for empirical (and in particular experimental) research. The reason is that theory alone gives little guidance so that equilibrium selection becomes mostly an empirical question. The leadership literature has since long recognized the importance of leaders as coordinators (see, e.g. Foss, 2001), but economics offers powerful tools, in particular the combination of game theory and incentivized experiments, that allow classifying and studying coordination problems in a more systematic way than it has been done so far in the leadership literature. In the following we provide a review of the the evidence on leader impact in coordination games that experimental economists have accumulated so far.

The classic workhorse used in studies on leadership in coordination games is the so called weakest-link game, in which payments to everyone in an organization depend only on the lowest effort chosen by one of its members (the weak link). This setup is reminiscent of the kinds of organizational processes mentioned above, in which a coordinated strategy is essential (Camerer and Knez, 1994). ${ }^{35}$ The earliest experimental evidence on such games was provided by van Huyck et al (1990). ${ }^{36}$ They study a game in which participants form groups (of various sizes), and each participant has to choose a number between 1 and 7 . The higher the chosen number, the higher are the associated costs for the participant. However, monetary returns depend on the lowest number chosen within the group. More precisely, the payoff function is given by $\pi_{\mathrm{i}}=0.6+0.2 \min \left[\mathrm{x}_{\mathrm{i}}, \mathrm{x}_{-\mathrm{i}}\right]-0.1 \mathrm{x}_{\mathrm{i}}$. The payoffs associated with different combinations of the own chosen number and the minimal number chosen by some group member are reproduced in Table 2.

Since choosing higher numbers is costly, but does not result in higher returns --- unless the own number turns out to be the lowest number in the group --- individual group members have no individual incentives to raise their own number above what they believe will be the lowest number picked by another member of their group. From a game

\footnotetext{
${ }^{34}$ In economics that term "common knowledge" is used in a particular way. In our case it describes a belief system in which everybody believes that all others are motivated, and everybody believes that all others believe that everybody is motivated, and everybody believes that all others believe that all others believe that everybody is motivated, and so on.

${ }^{35}$ A closely related theory of production is the so called O-Ring theory (Kremer, 1993), which compares production processes to chains that are only as strong as their weakest link.

${ }^{36}$ This experimental paradigm has subsequently become the standard design to study coordination problems experimentally.
} 
theoretic perspective, this implies that the game has multiple equilibria. If every group member picks a 7, it turns out that it is indeed individually optimal for every group member to pick a 7. Unilaterally lowering one's number to 6 would reduce returns (because 6 would now be the lowest number) and the loss in return would be larger than the reduction of costs. If every group member picks a 6, however, it is individually optimal for every group member to pick a 6. Raising the own number to 7 would create a cost without additional benefit, since the lowest number within the group would remain at 6 . Unilaterally lowering the number to 5 is also not a profitable deviation, because it would lead to a larger decrease in return than in costs. The same logic applies to all numbers. Hence, each situation in which all group members choose the same number, independent of which number it is, constitutes a Nash Equilibrium of the game (i.e., no participant has incentives to unilaterally change his strategy). However, from an efficiency point of view, it is important that participants coordinate on a high number, because the higher the number people coordinate on, the higher their payoff (see Table 2).

Table 2: Reproduction of Payoff Table A in van Huyck, Batallio and Beil (1990).

\begin{tabular}{|c|c|c|c|c|c|c|c|c|}
\hline \multicolumn{2}{|c}{} & \multicolumn{7}{|c|}{ Smallest Value of X Chosen } \\
\cline { 2 - 10 } & 7 & 6 & 5 & 4 & 3 & 2 & 1 \\
\hline \multirow{4}{*}{$\begin{array}{c}\text { Your } \\
\text { Choice of }\end{array}$} & 7 & $\mathbf{1 . 3}$ & 1.1 & 0.9 & 0.7 & 0.5 & 0.3 & 0.1 \\
\cline { 2 - 10 } & 5 & - & $\mathbf{1 . 2}$ & 1.0 & 0.8 & 0.6 & 0.4 & 0.2 \\
\cline { 2 - 10 } & 4 & - & - & $\mathbf{1 . 1}$ & 0.9 & 0.7 & 0.5 & 0.3 \\
\cline { 2 - 10 } & 3 & - & - & - & - & $\mathbf{0 . 9}$ & 0.7 & 0.5 \\
\cline { 2 - 10 } & 2 & - & - & - & - & - & $\mathbf{0 . 8}$ & 0.6 \\
\cline { 2 - 10 } & 1 & - & - & - & - & - & - & $\mathbf{0 . 7}$ \\
\hline
\end{tabular}

Note: Nash equilibrium outcomes are marked in bold.

The experimental evidence from these games shows that coordination failure is very common. Most groups do not obtain efficient coordination on the highest possible number, but rather get trapped in worse, low number equilibria. 
The authors attribute these results to the imminent strategic uncertainty that is present in strategic interactions with complementarities like the weakest-link game. As explained above, a bit of pessimism is sufficient to induce people to lower their contribution and this is what these results reflect.

The degree of strategic uncertainty, however, is affected by various game parameters that are subject to change. Consequently, effective leaders can use and alter these parameters in order to reduce strategic uncertainty, increase the alignment of beliefs, and lead their teams to more efficient outcomes. Among these parameters are, most notably, the group size, financial incentives, communication and leading by example.

Group size was already manipulated in the early experiments by van Huyck et al. (1990). If groups only consisted of 2 members, instead of 16, efficient coordination was achieved much more frequently. Weber (2006) extends the analysis of group size and shows that groups that start small and then grow slowly can sustain efficient cooperation if entrants into the group observe previous group behavior. If the small group was coordinated efficiently, new entrants were willing to coordinate accordingly. Consequently, one task of a leader can consist in managing the growth of groups in order to sustain coordination.

A leader could also use classical transactional tools to improve coordination problems. Brandts and Cooper (2006) study a "corporate turnaround game", which builds on the weakest-link games introduced before. In the corporate turnaround game, firm profits depend on the minimum effort level chosen by one of the "workers" in the firm. The game is played repeatedly among the same set of workers, but the "bonus rate" varies across rounds. The bonus rate determines the extent to which workers participate in the coordination profits. The authors show that workers coordinate on low effort levels if bonus rates are low, but improve coordination if bonus rates increase. Interestingly, large increases in bonus rates lead to no larger improvements than small increases. ${ }^{37}$ Moreover, decreasing bonuses in situations in which groups were efficiently coordinated did not lead to less efficient coordination. This implies that leaders are able to move groups from inefficient to efficient equilibria in coordination problems by temporarily using transactional tools.

Another strategic tool at hand of the leader is communication. Cooper et al. (1992) show that one-way communication improves outcomes in coordination games of the type explained above, but simultaneous two-way communication does not always achieve such improvements. The reason is that simultaneous two-way communication can result in conflicting messages, whereas a single leader can clearly communicate the team strategy, which in turn is more

\footnotetext{
${ }^{37}$ Similar results were found in Hamman, Rick and Weber (2007).
} 
effective in aligning beliefs. If communication is not possible, leaders can also coordinate beliefs through "leading by example". Cartwright et al. (2013) show that a publicly observed leader who moves first can improve coordination outcomes since the example set by the leader helps aligning beliefs.

The strengths of experimental methodology is not restricted to its possibility to causally evaluate the effect of interventions like communication and incentives, but also to compare the effectiveness of different interventions. Using again the corporate turnaround game, Brandts and Cooper (2007) compare communication by a leader to changes in the financial incentives. They find that communication is more effective and more profitable to the leader than incentive increases in improving coordination. Brandts, Cooper and Weber (2015) replicate these findings, but in addition exogenously vary the legitimacy of the leader. They find that elected leaders were significantly more effective in inducing change to more efficient equilibria than randomly selected leaders.

Experiments have also been used to test the effectiveness of transformational interventions for coordination. An experiment by Chen and Chen (2011) informs on the idea that charismatic leaders can act as creators of identity. They show that inducing a group identity in a group, prior to playing a weakest-link game, increases efficient coordination of the group. These findings confirm that identity creation not only aligns incentives, but also helps to coordinate beliefs.

Experiments not only enable to study the difference in effectiveness of elected and randomly assigned leaders, they also allow assessing determinants of leader emergence. Brandts, Cooper and Fatas (2007), for example, using a coordination game in which players differ in their costs of choosing higher numbers, show that leaders are more effective and more likely to be chosen as leaders if they are more similar to their fellow co-workers, i. e., if a majority of workers shares their costs of providing effort. Apparently, similarity increases credibility and leads to higher effectiveness.

The empirical literature covered so far was concerned with situations, in which interests of the leader and followers were always fully aligned. In those cases the leader's task was purely one of equilibrium selection, in that she needed to make sure that followers coordinate their beliefs in such a way that the efficient equilibrium is picked. However, in reality the situation is sometimes complicated by the presence of asymmetric information and conflicts of interests between the leader and her followers. In those cases coordination is more difficult to achieve, because the followers anticipate that the leader is not necessarily motivated to tell the truth and the leader needs to convince them of her credibility. Hermalin (1998) provides a theoretical framework that allows studying such situations. His framework is 
a version of the team production problem that we already discussed in the section on foundations of leadership (Alchian and Demsetz, 1972; Homström, 1999). However, there are two additional twists that make the situation more challenging. First, it is assumed that monitoring is too expensive and cannot be used to solve the free-riding problem. Second, there is also informational asymmetry in that the leader is the only one who knows how productive the followers' effort contributions are. ${ }^{38}$ For efficiency reasons it would be important that the leader can credibly communicate the productivity of effort to the followers, but because the leader always benefits if the followers provide high effort, she always has an incentive to claim that productivity is high. There are two interesting solutions that allow the leader to address her credibility problem. The first one is leading by sacrifice. This solution is based on a contract that turns the leader's compensation into a function of her productivity announcement. The contract is structured such that the leader needs to make a "sacrifice" if she announces a high productivity. The sacrifice needs to be high enough so that the leader is only willing to make it if productivity is really high, but the sacrifice also needs to be small enough so that the leader is better off by making the sacrifice than by not making it. In reality leader sacrifices correspond, for example, to announcements of extra bonus payments or a big party after successful completion of a project. The intuition is that the leader is only willing to cover these additional expenses if the project is really profitable. The second solution is leading by example. In this case the leader decides to move first and make her own effort observable to the followers. Because the leader's willingness to exert high effort depends on the productivity, her effort is a credible signal and it becomes optimal for followers to simply mimic the behavior of the leader. The leading by example solution has found empirical support in several experimental investigations (Potters et al., 2005, 2007, Gaechter and Renner, 2014). ${ }^{39}$ This evidence consistently shows that effective leaders can overcome coordination problems even in situations in which informational asymmetries severely complicate the formation of trust between the leader and her followers. ${ }^{40}$

\footnotetext{
${ }^{38}$ The assumption that the leader has superior knowledge links this work to recent studies in the leadership literature pointing out the importance of extending the full-range approach to also include instrumental leadership (Antonakis and House, 2014). An important part of the instrumental approach consists in expert-based leadership. Hermalin (1998) and the work building on it can be seen as simple attempts to capture the notion of expert leaders in an economic model.

${ }^{39}$ Meidinger and Villeval (2002) point out that the pattern observed in these experiments is also consistent with a reciprocity interpretation and does not necessarily support the signaling story.

${ }^{40}$ Hermalin's work has also triggered an interesting series of theoretical extensions. Hermalin (2007) explores a repeated version of the game and emphasizes that reputational incentives can discipline the leader to tell the truth if followers reward truth telling with tribute. Komai et al. (2007) show that organizations may have reasons to limit what the leader can credibly communicate, because there are situations in which keeping information from the follower can be beneficial. Andreoni (2006), Huck and ReyBiel (2006) and Kobayashi and Suehiro (2005) use a version of the framework to study leader emergence (see also the section on leader emergence above).
} 


\section{Ensuring Credibility in Relational Contracts}

Shaping follower beliefs is also important in the context of so called relational contracts. Relational contracts are selfenforcing, informal agreements in long-term relationships (Bull, 1987, Baker et al., 1994, Levin, 2003, see Malcomson, 2013 for a full survey of the corresponding literature). Such informal agreements are highly relevant whenever important aspects of the work relationships (such as the output produced by the follower) can only be observed by those directly involved in the process but not by outsiders like the legal authorities. In such situations leaders cannot motivate followers through formal contracts, because the non-observability to outsiders implies that such contracts would not be legally enforceable. To illustrate the basic mechanism underlying relational contracts, let us consider a simple example. Imagine that there is a leader and a follower who interact with each other. Each party can choose one of two strategies. The follower can either "work hard" or "be lazy". The leader can "pay a bonus" or "not pay a bonus". If the follower decides to work hard he creates a net surplus of 16 . If the leader decides to pay the bonus, the surplus is equally split between the two (i.e., each one gets a payoff of 8). If the leader does not pay the bonus, she keeps the bigger share of the surplus (14) and the follower only gets a very small part (2). If the follower decides to be lazy, in contrast, total surplus only amounts to 10. If the leader pays the bonus in this situation, the worker gets a payoff of 12 and the leader loses 2 points. If the leader holds back the bonus, the leader gets a payoff 4 , while the follower makes a payoff of 6 . The following matrix (see Table 3) shows the payoffs of the two players as a function of their decisions (for each strategy combination the first number represents the leader's payoff and the second number stands for the follower's payoff): ${ }^{41}$

Table 3: A Bonus-Effort Game

\begin{tabular}{|l|l|c|c|}
\hline \multicolumn{2}{|c|}{} & \multicolumn{2}{c|}{ Follower } \\
\cline { 3 - 4 } \multicolumn{2}{|l|}{} & Work hard & \multicolumn{2}{c|}{ Bazy } \\
\hline \multirow{2}{*}{ Leader } & Bonus & 8,8 & 4,6 \\
\cline { 2 - 4 } & No bonus & 14,2 & 42 \\
\hline
\end{tabular}

\footnotetext{
${ }^{41}$ For simplicity, we present the game as a simultaneous-move situation in which the leader's bonus payment and the follower's work intensity are determined at the same time. It might be more natural to think about this situation as a sequential-move structure in which the leader chooses the bonus after the follower has determined his work intensity. Such a move structure would complicate the exposition and change the details of the analysis, but the general implications would remain unaffected.
} 
In this game, efficiency requires that the follower decides to work hard. Unfortunately, however, the payoff structure is such that "being lazy" is a dominant strategy for the follower (i.e., no matter whether the leader pays the bonus or not, being lazy always benefits the follower). Likewise, it is never optimal for the leader to pay the bonus, because keeping the bonus to herself increases the payoff irrespective of the follower's decision. Thus, if this game is only played once, the unique equilibrium is that the follower decides to be lazy and the leader pays no bonus. In an organizational setting, this type of behavior would of course be highly ineffective.

If this game is played repeatedly, however, a "relational contract" between the parties may allow to achieve a better outcome. Assume that the leader and the follower do not know exactly for how many times they will interact with each other (suppose, for example, that there is an exogenous, positive termination probability after each round of interaction). Relational contracts specify contingent plans of action based on the history of observed behavior. For example, a relational contract in the leader-follower situation depicted above may take the following form: "The follower works hard and the leader pays the bonus in every period. If it is ever observed that one or both parties deviate from this agreed-upon strategy pair, both players will revert to their dominant strategies in the stage game for all following periods." Intuitively, the relational contract determines cooperation as the benchmark action, and also specifies a punishment strategy in case one of the team members deviates from the relational contract. Although such a contract will never be enforced by a court, the agreement is indeed sustainable, or self-enforcing, if the future punishment specified in the agreement is strong enough to outweigh the immediate benefits of deviant behavior today. The consequences of breaching the relational contract above would be as follows: If the leader decides not to pay the bonus in a given period, this will increase her immediate payoff by 6 units (from 8 to 14). However, since the parties revert to the strategy combination "no bonus"-"being lazy" after such an event, the leader would lose 4 units in each single future period. It is easy to see that deviating from the agreed upon strategies is not attractive if the leader expects the interaction to continue for several periods (actually, it suffices that the leader believes that the game continues in expectation for at least 2 periods). A similar analysis applies for the follower. Being lazy in a particular period would increase the immediate payoff by 4 units, but the loss in every future period would be 2 units. Thus if the follower believes that the game continues in expectation for more than two periods, deviating from the relational contract is 
not attractive. Therefore, if the leader and the follower have sufficiently optimistic beliefs about the length of their future interaction, the relational contract is self-enforcing. ${ }^{42}$

However, to understand the role of the leader in this situation, it is important to notice that the relational contract described above is by no means the only equilibrium that exists in this situation. There is a famous theorem in game theory -- the so-called Folk Theorem -- that says that in a game with an unknown number of periods (in economics this is usually called an infinitely repeated game) there are always many equilibria. Unfortunately, the set of equilibria also includes very bad ones. In our case, for example, it is also an equilibrium that the two parties play the equilibrium in dominant strategies in each period, i.e., the follower is always lazy and the leader never pays the bonus. ${ }^{43}$ Thus, exactly as in the coordination games discussed above the role of the leader is the one of a coordinator of beliefs. The task is to make sure that the leader and the follower agree on a relational contract that contains a set of rules which make sure that an efficient equilibrium is picked from the large set of available equilibria. ${ }^{44}$

\section{Novel Avenues: The Leader as a Creator of Clarity}

Depending on the environment coordination in relational contracts can be quite difficult. In the simple example discussed in the previous section the leader and the follower played the exact same game in every period of their repeated interaction. As a consequence, coordination on an efficient equilibrium seemed to be relatively easy. In reallife, in contrast, the world is not always as stationary. Interaction environments frequently change in quite fundamental ways and interaction partners are often confronted with new and possibly unexpected situations. In such situations the coordination problem is substantially more complicated, because there is an imminent danger that misunderstandings lead to problems. In an attempt to provide an illustrative example for the kinds of problems that can emerge in nonstationary environments Gibbons and Henderson (2012) refer to Stewart's (1993) account of the takeover of the investment bank First Boston by Credit Suisse: "Roughly speaking, in the first two years that Credit Suisse controlled Credit Suisse First Boston (CSFB), all firms in the investment banking industry performed poorly and employees (at CSFB) received bonuses that were lower than the historical average but comparable to bonuses paid at other

\footnotetext{
42 Zupan (2010) argues that leadership is about transforming such one-shot prisoner's dilemma games into repeated interactions in order to increase efficiency.

${ }^{43}$ To see that this repeated play of the stage-game equilibrium is an equilibrium in the repeated game, it suffices to realize that no player has an incentive to change his or her strategy given the strategy of the other player (i.e., given that the follower never works hard, the leader never has an incentive to pay a bonus and vice-versa).

${ }^{44}$ In this section we have emphasized how a long time horizon can help to overcome incentive problems. However, Holmström (1999b) shows that in the presence of incongruities between the follower's concern for human capital and the leader's concern for financial returns time does not need to be blessing, but can also create additional incentive problems. To what extent leadership tactics can be used to mitigate some of these problems is an interesting question for future research.
} 
investment banks. In the third year, however, CSFB performed better than it had and yet worse than its competitors, and Credit Suisse paid bonuses that were above bonuses at CSFB in the first two years but lower than those at other firms in the third year. A crisis ensued. In brief, CSFB asserted that the bonus policy in its industry was "match the market," meaning that bonuses should be competitive with bonuses at other top-bracket firms. In contrast, the Swiss asserted that in its industry the bonus policy was "pay for performance," meaning that a banker's bonus depended on how he and his bank performed." (Gibbons and Henderson, 2012, p. 1359)

This example illustrates the intricacies involved in the management of relationships. In non-stationary environments the meaning and interpretation of cooperative and efficient actions that are in the spirit of the relational contract may depend on (potentially unforeseen) contingencies in any given period and they may change over time. As a consequence, misunderstandings between interacting parties are likely to arise. In the example of CSFB, the third year revealed different understandings of the bonus culture implied in the relationship between the Swiss and American branches of the bank. While previous First Boston bankers interpreted the relational contract as "match the market", the Swiss paid bonuses according to "pay for performance". It took 3 years for these misunderstandings to surface, and when they did it was too late to prevent a major crisis within the bank.

Based on these observations, Gibbons and Henderson (2012, 2013) argue that effective relational contracts must not only solve the so called credibility problem that we described in the example in the previous section, but the twin problems of credibility and clarity. As the CSFB example shows, many relationships break down not because one trading party willingly violated the informal agreement, but because there was a misunderstanding of what the agreement actually was. Clarity is therefore not about whether parties can credibly communicate that they will honour their agreement in the relational contract, but rather about whether they actually understand what kind of action is required from each party in each (possibly unforeseen) circumstance. Such understanding is difficult to achieve in a non-stationary world, in which different actions are required by each party conditional on changing external circumstances in order to achieve the efficient, cooperative outcome.

Gibbons and Henderson argue that, in order to develop a broad enough shared understanding of the relational contract and to avoid cooperation break-downs in such situations, one must achieve not only common task knowledge, but also relational knowledge. Task knowledge comprises only the specific actions to be taken by each involved party, such as specifying that the follower is supposed to work hard and the leader is expected to pay the bonus. Relational knowledge comprises knowledge of all the consequences of one's actions for all involved parties. Only in case of 
common relational knowledge does each team member know how effective and important his contribution is in a particular contingency. Because unforeseen contingencies often affect consequences of actions, but do not affect the actions themselves that are available to parties, lack of relational knowledge can lead to misunderstandings and in turn to relationship break-downs.

The importance of relational knowledge implies a new, additional role for the leader in the management of relational contracts which goes well beyond the one of a simple coordinator: The leader has to serve as a clarifier of the general principles underlying the relational contract. Effective leaders manage to understandably communicate the terms of relational contracts and to create the common task and relational knowledge that is required to sustain them. In doing so, they create competitive advantages to their firms that cannot be easily mimicked by their competitors. Provision of relational knowledge cannot be achieved in an instant. It requires time and the right personality and leadership style. Effective leaders may also be able to adjust relational contracts to changing environments. By creating the necessary relational knowledge for all involved parties, such adjustments can take place without causing relationship breakdowns due to misinterpretations of changed terms or actions. What kind of leadership style is required to effectively build common relational knowledge at all times and to adopt relational contracts based on such knowledge is an important avenue for future research. Given that leadership scholars have extensively studied the role of personal characteristics (Judge et al. 2002, 2004) and rhetorical tactics for effective communication (Antonakis et al., 2011, Awamleh and Gardner, 1999, Frese et al., 2003, Towler, 2003), it is crucial that this literature is consulted when making progress in this direction.

\section{Conclusion}

In writing this article, we had two objectives. First, we wanted to convince both economists and psychologists/management scholars that economics, with its core approach based on rational behavior and contracts, had something meaningful to say about leadership. Note that this is historically a difficult position to take since firms and organizations, let alone what was going on within them, have been largely neglected, as a field of study, by neoclassical economists for a very long time (Bolton et al., 2013a). The last 25 years have certainly changed this as the economics of organizations is now a well-established and still growing field, but within that field the role of leaders has not been seen as playing a major role. On the other hand, psychologists and management scholars building on psychology research have clearly dominated the research field, but with little attempts to bring economics insights 
into the picture. We believe it is important to change this, and we hope our paper can contribute to move things in this direction.

Our second objective in this paper was also to create bridges between the leadership literature and economic approaches to leadership. We are convinced that both perspectives have a tremendous explanatory potential individually, but also that creating a common ground for conversation and complementary developments would bring even more. As suggested in our section on leadership effectiveness, many of these connections are in fact already there and there exist interesting and promising ways in which economics can be used to further explore concepts such as transactional and transformational leadership. But these research avenues are still wide open. The work is thus well cut out for researchers willing to work at the frontier of these disciplines.

\section{References}

Aghion, Philippe, and Jean Tirole. 1997. “Formal and Real Authority in Organizations.” Journal of Political Economy 105(1): 1-29.

Akerlof, George A., and Rachel E. Kranton. 2000. “Economics and Identity.” Quarterly Journal of Economics 115(3): 715-53.

Akerlof, George A., and Rachel E. Kranton. 2005. "Identity and the Economics of Organizations." Journal of Economic Perspectives 19(1): 9-32.

Akerlof, George A., and Rachel E. Kranton. 2010. "Identity Economics: How Our Identities Shape Our Work, Wages, and Well-Being." Princeton University Press.

Alchian, Armen A., and Harold Demsetz. 1972. "Production, Information Costs, and Economic Organization." American Economic Review 62(5): 777-795.

Andreoni, James. 2006. "Leadership giving in charitable fundraising.” Journal of Public Economic Theory 8(1): 1-22.

Antonakis, John, Marika Fenley, and Sue Liechti. 2011. “Can Charisma Be Taught? Tests of Two Interventions.” The Academy of Management Learning and Education, 10(3): 374-396.

Arrow, Kenneth J. 1951. "Social Choice and Individual Values.” First Edition, Wiley, New York.

Arrow, Kenneth J., and Gerard Debreu. 1954. "Existence of an equilibrium for a competitive economy." Econometrica 22(3): 265-290.

Avolio, Bruce J., Rebecca J. Reichard, Sean T. Hannah, Fred O. Walumbwa, and Adrian Chan. 2009. "A meta-analytic review of leadership impact research: Experimental and quasi-experimental studies." Leadership Quarterly 20 (5): 764-784.

Awamleh, Raed, and William L. Gardner. 1999. "Perceptions of leader charisma and effectiveness: The effects of vision content, delivery, and organizational performance." Leadership Quarterly 10(3): 345-373.

Baker, George P. 1992. "Incentive Contracts and Performance Measurement.” Journal of Political Economy 100(3): 598-614. 
Baker, George P., Robert Gibbons, and Kevin J. Murphy. 1994. "Subjective Performance Measures in Optimal Incentive Contracts.” Quarterly Journal of Economics: 1125-1156.

Baker, George P., Robert Gibbons, and Kevin J. Murphy. 1999. "Informal authority in organizations." Journal of Law, Economics, and organization 15(1): 56-73.

Bandiera, Oriana, Iwan Barankay, and Imran Rasul. 2005. "Social preferences and the response to incentives: Evidence from personnel data."Quarterly Journal of Economics 120(3): 917-962.

Bartling, Björn, Ernst Fehr, and Holger Herz. 2014. "The intrinsic value of decision rights." Econometrica 82(6): 2005-2039.

Bass, Bernard M. 1985. "Leadership and Performance Beyond Expectations.” New York: The Free Press.

Bass, Bernard M. 1990. "From transactional to transformational leadership: Learning to share the vision." Organizational Dynamics 18(3): 19-31.

Bass, Bernard M. 1995. “Theory of Transformational Leadership Redux.” Leadership Quarterly 6(4): 463-478.

Bass, Bernard M. 1998. "Transformational leadership: Industry, military, and educational impact.” Mahwah, NJ: Erlbaum.

Bass, Bernard M. 1999. “Two decades of research and development in transformational leadership.” European Journal of Work and Organizational Psychology, 8, 9-32.

Bendahan, Samuel, Christian Zehnder, Francois Pralong and John Antonakis. 2015. "Leader corruption depends on power and testosterone." Leadership Quarterly 26(2): 101-122.

Blanes i Vidal, Jordi and Marc Möller. 2007. "When should leaders share information with their subordinates?." Journal of Economics \& Management Strategy 16(2): 251-283.

Blomberg, Brock S., Gregory D. Hess, and Yaron Raviv. 2009. "Where have all the heroes gone? A rational choice perspective on heroism.” Public Choice. 141(3/4): 509-522.

Bolton, Patrick, Markus K. Brunnermeier, and Laura Veldkamp. 2013a. "Economists’ Perspectives on Leadership." in: Handbook of Leadership Theory and Practice: An HBS Centennial Colloquium on Advancing Leadership. Harvard Business Press.

Bolton, Patrick, Markus K. Brunnermeier, and Laura Veldkamp. 2013b. "Leadership, coordination, and corporate culture." Review of Economic Studies 80(2): 512-537.

Brandts, Jordi, and David J. Cooper. 2006. “A change would do you good.... An experimental study on how to overcome coordination failure in organizations.” American Economic Review 96(3): 669-693.

Brandts, Jordi, and David J. Cooper. 2007. "It's what you say, not what you pay: an experimental study of manageremployee relationships in overcoming coordination failure." Journal of the European Economic Association, 5(6): 1223-1268.

Brandts, Jordi, David J. Cooper, and Enrique Fatas. 2007. "Leadership and Overcoming Coordination Failure with Asymmetric Costs.” Experimental Economics 10(3): 269-284.

Brandts, Jordi, David J. Cooper, and Roberto A. Weber, 2015. "Legitimacy, Communication, and Leadership in the Turnaround Game.” Management Science 61(11): 2627-2645.

Bryman, Alan. 1992. "Charisma and leadership in organizations.” Sage Publications.

Bull, Clive. 1987. "The existence of self-enforcing implicit contracts." Quarterly Journal of Economics: 147-159.

Burns, James M. 1978. “Leadership.” New York: Harper \& Row.

Camerer, Colin and Marc Knez. 1994. "Creating Expectational Assets in the Laboratory: Coordination in 'WeakestLink’ Games.” Strategic Management Journal 15(S1): 101-119. 
Cartwright, Edward, Joris Gillet, and Mark Van Vugt. 2013. "Leadership by Example in the Weak-Link Game." Economic Inquiry 51(4): 2028-2043.

Chattopadhyay, Raghabendra, and Esther Duflo. 2004. "Women as policy makers: Evidence from a randomized policy experiment in India." Econometrica 72(5): 1409-1443.

Chen, Roy, and Yan Chen. 2011. "The Potential of Social Identity for Equilibrium Selection.” American Economic Review 101(6): 2562-2589.

Clots-Figuerasa, Irma. 2012. “Are female leaders good for education?” American Economic Journal: Applied Economics 4(1): 212-244.

Coase, Ronald. 1937. "The nature of the firm.” Economica, 4(16): 386-405.

Coffman, Katherine B. 2014. "Evidence on Self-Stereotyping and the Contribution of Ideas." Quarterly Journal of Economics, 129(4): 1625-1660.

Cooper, Russell, Douglas V. DeJong, Robert Forsythe, and Thomas W. Ross. 1992. "Communication in Coordination Games.” Quarterly Journal of Economics 107(2): 739-771.

D'Adda, Giovanna, Darai, Donja, Pavanini, Nicola and Weber, Roberto. 2016. "Do leaders affect ethical outcomes?" Journal of the European Economic Association (in press).

Danz, David, Dorothea Kübler, Lydia Mechtenberg, and Julia Schmid. 2015. "On the failure of hindsight-biased principals to delegate optimally." Management Science 61(8): 1938-1958.

Debreu, Gerard. 1951. "The coefficient of resource utilization." Econometrica: Journal of the Econometric Society: 273-292.

Deci, Edward L. and Richard M. Ryan. 1975. “Intrinsic motivation.” John Wiley \& Sons, Inc.

Dohmen, Thomas, and Armin Falk. 2011. "Performance pay and multidimensional sorting: Productivity, preferences, and gender." American Economic Review 101(2): 556-590.

Eagly, Alice H., and John Antonakis. 2015. "Leadership.” APA Handbook of Personality and Social Psychology. Volume 1: Attitude and Social Cognition. M. Mikulincer and P.R Shaver (Eds), The American Psychological Association. Chapter 18: 571-592.

Elsbach, Kimberly D., and Roderick M. Kramer. 1996. "Members' responses to organizational identity threats: Encountering and countering the Business Week rankings”, Administrative Science Quarterly, 41: 442-476.

Fehr, Ernst and Lorenz Goette. 2007. "Do Workers Work More if Wages Are High? Evidence from a Randomized Field Experiment." American Economic Review 97(1): 298-317.

Fehr, Ernst, Holger Herz, and Tom Wilkening. 2013. "The lure of authority: Motivation and incentive effects of power." American Economic Review 103(4): 1325-1359.

Feltham, Gerald A., and Jim Xie. 1994. "Performance Measure Congruity and Diversity in Multi-Task Principal/Agent Relations." The Accounting Review 69(3): 429-453.

Foss, Nicolai J. 2001. “Leadership, Beliefs and Coordination: An Explorative Discussion.” Industrial and Corporate Change 10(2): 357-388.

Frese, Michael, Susanne Beimel, and Sandra Schoenborn. 2003. "Action training for charismatic leadership: Two evaluations of studies of a commercial training module on inspirational communication of a vision." Personnel Psychology 56(3): 671-698.

Gaechter, Simon, and Elke Renner. 2014. "Leaders as Role Models for the Voluntary Provision of Public Goods." CESifo Working Paper Series No. 5049.

Gangadharan, Lata, Tarun Jain, Pushkar Maitra, and Joe Vecci. (2016). "Social Identity and Governance: The Behavioral Response to Female Leaders.” European Economic Review (in press). 
Gervais, Simon, and Itay Goldstein. 2007. "The positive effects of biased self-perceptions in firms." Review of Finance 11(3): 453-496.

Gibbons, Robert, and Rebecca Henderson. 2012. "Relational Contracts and Organizational Capabilities.” Organization Science 23(5): 1350-1364.

Gibbons, Robert, and Kevin J. Murphy. 1990. "Relative performance evaluation for chief executive officers."

Industrial \& Labor Relations Review 43, no. (3): 30S-51S.

Gibbons, Robert, and Rebecca Henderson. 2013. "What do Managers Do?.” in Gibbons, Robert, and John Roberts (Eds.), The handbook of organizational economics, Princeton University Press.

Gibbons, Robert, and John Roberts. 2013. "Economic Theories of Incentives in Organizations”, in Gibbons, Robert, and John Roberts (Eds.), The handbook of organizational economics, Princeton University Press.

Gioia, Dennis A., and James B. Thomas. 1996. "Identity, image and issue interpretation: Sensemaking during strategic change in academia.” Administrative Science Quarterly 41: 370-403.

Goodall, Amanda H., and Ganna Pogrebna. 2015. "Expert leaders in a fast-moving environment." Leadership Quarterly 26(2): 123-142.

Goodpaster, Kenneth E. and Robert J. Post. 1981. "HJ Heinz: The Administration of Policy.” Harvard Business School Case, (382-036). Grabo, Allen., and Mark van Vugt. (in press). "Charismatic leadership and the evolution of cooperation." Evolution and Human Behavior.

Grossman, Sanford J., and Oliver D. Hart. 1986. "The Costs and Benefits of Ownership: A Theory of Vertical and Lateral Integration.” Journal of Political Economy 94(4): 691-719.

Hamman, John, Scott Rick, and Roberto A. Weber. 2007. "Solving coordination failure with "all-or-none" grouplevel incentives." Experimental Economics 10(3): 285-303.

Hart, Oliver. 2008. "Reference Points and the Theory of the Firm.” Economica 75(299): 404-411.

Hart, Oliver and Bengt Holmström. 1987. "The Theory of Contracts.” Advances in Economic Theory, Fifth World Congress, Cambridge University Press, Cambridge.

Hart, Oliver, and John Moore. 1990. "Property Rights and the Nature of the Firm.” Journal of Political Economy 98(6): 1119-1158.

Hermalin, Benjamin E. 1998. "Toward an Economic Theory of Leadership: Leading by Example." American Economic Review 88(5): 1188-1206.

Hermalin, Benjamin E. 2007. "Leading for the long term.” Journal of Economic Behavior \& Organization, 62(1): 119.

Hermalin, Benjamin E. 2013. "Leadership and Corporate Culture.” in Gibbons, Robert, and John Roberts (Eds.), The handbook of organizational economics, Princeton University Press.

Holmstrom, Bengt. 1982. "Moral hazard in teams." The Bell Journal of Economics 13(2): 324-340.

Holmstrom, Bengt. 1999a. "The firm as a subeconomy." Journal of Law, Economics, and Organization 15(1): 74-102.

Holmström, Bengt. 1999b. "Managerial Incentive Problems: A Dynamic Perspective.” Review of Economic Studies 66(1): 169-182.

Holmström, Bengt, and Paul Milgrom. 1987. "Aggregation and Linearity in the Provision of Intertemporal Incentives.” Econometrica 55(2): 303-328.

Holmström, Bengt, and Paul Milgrom. 1991. "Multitask Principal-Agent Analyses: Incentive Contracts, Asset Ownership, and Job Design.” Journal of Law, Economics \& Organization 8(SI): 24-52. 
Holmström, Bengt, and Paul Milgrom. 1994. "The Firm as an Incentive System." American Economic Review 84(4): 972-991.

House, Robert J. 1977. “A 1976 Theory of Charismatic Leadership.” In J. G. Hunt \& L. L. Larson (Eds.), The Cutting Edge. Carbondale: Southern Illinois: University Press.

House, Robert J. 1996. "Path-goal theory of leadership: Lessons, legacy, and a reformulated theory." Leadership Quarterly 7(3): 323-352.

House, Robert J., Paul J. Hanges, S. Antonio Ruiz-Quintanilla, Peter W. Dorfman, Mansour Javidan, Marcus Dickson, and Vipin Gupta. 1999. "Cultural influences on leadership and organizations: Project GLOBE." Advances in global leadership 1(2): 171-233.

Howell, John M., and Bruce J. Avolio. 1993. "Transformational leadership, transactional leadership, locus of control, and support for innovation: Key predictors of consolidated business-unit performance.” Journal of Applied Psychology 78: 891-902.

Huck, Steffen, and Pedro Rey-Biel. 2006. "Endogenous leadership in teams." Journal of Institutional and Theoretical Economics JITE 162, no. 2: 253-261.

Jacob, Brian A. and Steven D. Levitt. 2003. "Rotten Apples: An Investigation of the Prevalence and Predictors of Teacher Cheating.” Quarterly Journal of Economics 118(3): 843-877.

Jensen, Michael C. and William H. Meckling. 1976. "Theory of the firm: Managerial behavior, agency costs and ownership structure.” Journal of Financial Economics 3(4): 305-360.

Jones, Benjamin F., and Benjamin A. Olken. 2005. "Do Leaders Matter? National Leadership and Growth Since World War II.” Quarterly Journal of Economics 120(3): 835-864.

Judge, Timothy A., Amy E. Colbert, and Remus Ilies. 2004. "Intelligence and leadership: a quantitative review and test of theoretical propositions." Journal of Applied Psychology 89(3): 542.

Judge, Timothy A., Joyce E. Bono, Remus Ilies, and Megan W. Gerhardt. 2002. "Personality and Leadership: A Qualitative and Quantitative Review.” Journal of Applied Psychology, 87(4): 765.

Judge, Timothy A., and Ronald F. Piccolo. 2004. "Transformational and Transactional Leadership: A Meta-Analytic Test of their Relative Validity." Journal of Applied Psychology 89(5): 765-780.

Kahneman, Daniel, and Amos Tversky. 1979. "Prospect Theory: An Analysis of Decision Under Risk.” Econometrica 47(2): 263-291.

Kobayashi, Hajime, and Hideo Suehiro. 2005. "Emergence of leadership in teams." Japanese Economic Review, 56(3): 295-316.

Komai, Mana, Mark Stegeman, and Hermalin, Benjamin E. 2007. "Leadership and information.” American Economic Review, 97(3): 944-947.

Kosfeld, Michael, and Susanne Neckermann. 2011. "Getting more work for nothing? Symbolic awards and worker performance.” American Economic Journal: Microeconomics: 86-99.

Kőszegi, Botond, and Matthew Rabin. 2006. “A Model of Reference-Dependent Preferences.” Quarterly Journal of Economics 121(4): 1133-1165.

Kremer, Michael. 1993. "The O-ring theory of economic development." Quarterly Journal of Economics 108(3): 551575.

Kulas, John T., Mana Komai, and Philip J. Grossman. 2013. "Leadership, information, and risk attitude: A game theoretic approach.” Leadership Quarterly 24(2): 349-362.

Lazear, Edward P., and Sherwin Rosen. 1981. "Rank-Order Tournaments as Optimum Labor Contracts." The Journal of Political Economy 89,(5): 841-864. 
Lazear, Edward P., and Paul Oyer. 2004. Personnel Economics. In R.Gibbons, \& J.Roberts (Eds.), Handbook of Organizational Economics: 479-519.

Lazear, Edward P. 2000. “The future of personnel economics.” Economic Journal 110(467): 611-639.

Levin, Jonathan. 2003. "Relational incentive contracts.” American Economic Review 93(3): 835-857.

Lord, Robert G., Christy L. De Vader, and George M. Alliger. 1986. "A Meta-Analysis of the Relation between Personality Traits and Leadership Perceptions: An Application of Validity Generalization Procedures." Journal of Applied Psychology 71(3): 402-410.

Malcomson, James M. 2013. "Relational Incentive Contracts". in Gibbons, Robert, and John Roberts (Eds.), The handbook of organizational economics, Princeton University Press.

Markóczy, Lívia. 2003. "Trust but verify: Distinguishing distrust from vigilance." Academy of Management Conference.

Mas-Colell, Andreu, Michael Dennis Whinston, and Jerry R. Green. 1995. "Microeconomic theory. Vol. 1.” New York: Oxford university press.

Matsa, David A., and Amalia R. Miller. 2013. "A female style in corporate leadership? Evidence from quotas." American Economic Journal: Applied Economics 5(3): 136-69.

McClelland, David C. 1975. "Power: The inner experience.” Irvington.

Meidinger, Claude, and Marie-Claire Villeval. 2002. "Leadership in teams: Signaling or reciprocating?” Working Paper.

Murphy, Kevin J. 1999. "Executive compensation.“ Handbook of labor economics (3) 2485-2563.

Niskanen, William A. 1971. "Bureaucracy and Representative Government.” Chicago: Aldine-Atherton.

Oc, Burak, Michael R. Bashshur, and Celia Moore. 2015. "Speaking truth to power: The effect of candid feedback on how individuals with power allocate resources.” Journal of Applied Psychology 100(2): 450.

Paarsch, Harry J., and Bruce S. Shearer. 1999. "The response of worker effort to piece rates: evidence from the British Columbia tree-planting industry.”Journal of Human Resources: 643-667.

Patterson, Gareth A. 1992. "New Jersey says Sears advised excess car repairs.” Wall Street Journal B3.

Potters, Jan, Martin Sefton, and Lise Vesterlund. 2005. "After you—endogenous sequencing in voluntary contribution games." Journal of Public Economics 89(8): 1399-1419.

Potters, Jan, Martin Sefton, and Lise Vesterlund. 2007. "Leading-by-example and signaling in voluntary contribution games: an experimental study." Economic Theory 33(1): 169-182.

Prendergast, Canice. 1999. "The Provision of Incentives in Firms." Journal of Economic Literature 37(1): 7-63.

Roberts, Johnnie L. 1989. “Credit Squeeze: Dun \& Bradstreet Faces Flap Over How It Sells Reports on. Businesses,” Wall Street Journal, March 2, 1989.

Rotemberg, Julio J, and Garth Saloner. 1993. "Leadership style and incentives.” Management Science 39(11): 12991318.

Rotemberg, Julio J, and Garth Saloner. 2000. "Visionaries, Managers, and Strategic Direction.” RAND Journal of Economics 31(4): 693-716.

Shadraconis, Sophon. 2013. “Organizational Leadership in Times of Uncertainty: Is Transformational Leadership the Answer?” LUX: A Journal of Transdisciplinary Writing and Research from Claremont Graduate University 2(1).

Shamir, Boas, Robert J. House, and Michael B. Arthur. 1993. “Organization Science 4(4): 577-594. 
Shearer, Bruce. 2004. "Piece rates, fixed wages and incentives: Evidence from a field experiment." Review of Economic Studies 71(2): 513-534.

Simon, Herbert A. 1991. "Organizations and markets." Journal of Economic Perspectives 5(2) (1991): 25-44.

Stewart, James. 1993. "Taking the dare." The New Yorker 69(23): 34-39.

Sturm, Rachel E., and John Antonakis. 2015. "Interpersonal Power A Review, Critique, and Research Agenda." Journal of Management 41(1): 136-163.

Towler, Annette J. 2003. "Effects of charismatic influence training on attitudes, behavior, and performance." Personnel psychology, 56(2): 363 - 381.

Tversky, Amos, and Daniel Kahneman. 1992. "Advances in Prospect Theory: Cumulative Representation of Uncertainty.” Journal of Risk and Uncertainty 5(4): 297-323.

Van den Steen, Eric. 2005. "Organizational beliefs and managerial vision.” Journal of Law, Economics, and organization, 21(1): 256-283.

Van den Steen, Eric. 2010. "Interpersonal Authority in a Theory of the Firm.” American Economic Review, 100(1): 466-490.

Van Huyck, John B., Raymond C. Battalio, and Richard O. Beil. 1990. "Tacit Coordination Games, Strategic Uncertainty, and Coordination Failure.” American Economic Review 80(1): 234-248.

Waldman, David A., Gabriel G. Ramirez, Robert J. House, and Phanish Puranam. 2001. "Does leadership matter? CEO leadership attributes and profitability under conditions of perceived environmental uncertainty."Academy of management journal 44(1): 134-143.

Waldman, Michael. 2004.“ Theory and Evidence in Internal Labor Markets.“ In Gibbons, and J.Roberts (Eds.), Handbook of Organizational Economics: 520-571.

Weber, Roberto. 2006. "Managing Growth to Achieve Efficient Coordination in Large Groups." American

Economic Review 96(1): 114-126.

Williamson, Oliver E. 1975. "Markets and Hierarchies." New York: The Free Press.

Williamson, Oliver E. 1985. “The Economic Institutions of Capitalism.” New York: The Free Press.

Zupan, Mark A. 2010. “An Economic Perspective on Leadership.” In N. Nohria and R. Khurana (eds.) Handbook of Leadership Theory and Practice, 265-90. Boston: Harvard Business Press. 


\begin{abstract}
Authors
Christian ZEHNDER

Professor of Organizational Behavior and Decision Making, University of Lausanne, Quartier UNIL-Dorigny Bâtiment Internef, 1015 Lausanne, Switzerland. e-mail: christian.zehnder@unil.ch;

Web: http://hec.unil.ch/people/czehnder\&vue=publications\&set_language=en\&cl=en

Holger HERZ

Chair for Industrial Economics, Department of Economics, University of Fribourg, Bd de Pérolles 90, 1700 Fribourg, Switzerland, and CESifo. E-mail: holger.herz@unifr.ch Web: http://www.unifr.ch/industrie/en/team/holger-herz

Jean-Philippe BONARDI

Department of Strategy, Globalization and Society, University of Lausanne, Quartier UNIL-Dorigny Bâtiment Internef room 604, 1015 Lausanne, Switzerland. email: jean-philippe.bonardi@unil.ch

Web: https://hec.unil.ch/hec/recherche/fiche?pnom=jbonardi\&dyn_lang=en
\end{abstract}

\begin{abstract}
Research on leadership in economics has developed in parallel to the literature in management and psychology and links between the fields have been sparse. Whereas modern leadership scholars mostly focus on transformational and related leadership styles, economists have mainly emphasized the role of contracts, control rights, and incentives. We argue that both fields could profit from enriching their approach with insights from the other field. We review and synthesize the economics literature on leadership in organizations and discuss how leadership scholars in management and psychology can benefit from the detailed understanding of transactional methods that economists have developed. We link the contributions in economics to a broad set of topics including the foundations of leadership, leader emergence, and leader effectiveness. At the same time, we also point out limitations of the economic approach and outline how the integration of leadership research and economics would broaden the scope of future studies.
\end{abstract}

\title{
Citation proposal
}

Christian Zehnder, Holger Herz, Jean-Philippe Bonardi. 2016. «A Productive Clash of Cultures: Injecting Economics into Leadership Research». Working Papers SES 478, Faculty of Economics and Social Sciences, University of Fribourg (Switzerland)

\section{Jel Classification}

D03, D21, D23, M50

\section{Keywords}

Leadership, Economics, Foundations, Emergence, Effectiveness

\section{Working Papers SES collection}

\section{Last published}

472 Huber M., Tyahlo S.: How war affects political attitudes: Evidence from eastern Ukraine; 2016

473 Deuchert E., Huber M., Schelker M.: Direct and indirect effects based on difference-in-differences with an application to political preferences following the Vietnam draft lottery; 2016

474 Grossmann V., Schäfer A., Steger T., Fuchs B.: Reversal of Migration Flows: A Fresh Look at the German Reunification; 2016

475 Pesenti A.: The Meaning of Monetary Stability; 2016

476 Furrer O., Sudharshan D., Tsiotsou Rodoula H., Liu Ben S. : A Framework for Innovative Service Design; 2016

477 Herz H., Taubinsky D.: What Makes a Price Fair? An Experimental Study of Transaction Experience and Endogenous Fairness Views; 2016

\section{Catalogue and download links}

http://www.unifr.ch/ses/wp

http://doc.rero.ch/collection/WORKING_PAPERS_SES

\section{Publisher}

Université de Fribourg, Suisse, Faculté des sciences économiques et sociales Universität Freiburg, Schweiz, Wirtschafts- und sozialwissenschaftliche Fakultät University of Fribourg, Switzerland, Faculty of Economics and Social Sciences
Bd de Pérolles 90, $\mathrm{CH}-1700$ Fribourg

Tél.: +41 (0) 263008200

decanat-ses@unifr.ch www.unifr.ch/ses 